\title{
Distinction between externally vs. internally guided decision-making: operational differences, meta-analytical comparisons and their theoretical implications
}

\author{
Takashi Nakao ${ }^{1,2}{ }^{*}$, Hideki Ohira ${ }^{3}$ and Georg Northoff ${ }^{1}$ \\ 1 Mind, Brain Imaging and Neuroethics, Institute of Mental Health Research, Royal Ottawa Health Care Group, University of Ottawa, Ottawa, ON, Canada \\ 2 Japan Society for the Promotion of Science, Tokyo, Japan \\ ${ }^{3}$ Graduate School of Environmental Studies, Nagoya University, Nagoya, Japan
}

\section{Edited by:}

Gabriel José Corrêa Mograbi, Federal University of Mato Grosso, Brazil

\section{Reviewed by:}

Gabriel José Corrêa Mograbi, Federal University of Mato Grosso, Brazil Willem Huijbers, Harvard Medical School, USA

Bernard J. Baars, The Neurosciences Institute, USA

\section{${ }^{*}$ Correspondence:}

Takashi Nakao, Mind, Brain Imaging and Neuroethics, Institute of Mental Health Research, Royal Ottawa Health Care Group, University of Ottawa, 1145 Carling Avenue, Room 6440, Ottawa, ON K1Z 7K4, Canada. e-mail: takana818@gmail.com
Most experimental studies of decision-making have specifically examined situations in which a single less-predictable correct answer exists (externally guided decision-making under uncertainty). Along with such externally guided decision-making, there are instances of decision-making in which no correct answer based on external circumstances is available for the subject (internally guided decision-making). Such decisions are usually made in the context of moral decision-making as well as in preference judgment, where the answer depends on the subject's own, i.e., internal, preferences rather than on external, i.e., circumstantial, criteria. The neuronal and psychological mechanisms that allow guidance of decisions based on more internally oriented criteria in the absence of external ones remain unclear. This study was undertaken to compare decision-making of these two kinds empirically and theoretically. First, we reviewed studies of decision-making to clarify experimental-operational differences between externally guided and internally guided decision-making. Second, using multi-level kernel density analysis, a whole-brain-based quantitative meta-analysis of neuroimaging studies was performed. Our meta-analysis revealed that the neural network used predominantly for internally guided decision-making differs from that for externally guided decision-making under uncertainty. This result suggests that studying only externally guided decision-making under uncertainty is insufficient to account for decision-making processes in the brain. Finally, based on the review and results of the meta-analysis, we discuss the differences and relations between decision-making of these two types in terms of their operational, neuronal, and theoretical characteristics.

Keywords: preference, moral judgment, default-mode network, conflict, medial prefrontal cortex, social situation resting state, fMRI

\section{INTRODUCTION}

How the human brain predisposes us to make certain choices while not making others is an important question that is often explored in current neuroscience (Bechara et al., 2000; O’Doherty, 2004, 2007; Sanfey et al., 2006; Volz et al., 2006; Wallis, 2007; Platt and Huettel, 2008; Rangel et al., 2008; Rilling et al., 2008b; Rolls and Grabenhorst, 2008; Sanfey and Chang, 2008; Vorhold, 2008; Balleine and O’Doherty, 2010; Ohira et al., 2010). Most experimental studies of decision-making have addressed situations in which one particular more or less-predictable answer is available. Although such studies particularly addressing lowpredictability include uncertainty related to an answer (Platt and Huettel, 2008; Rushworth and Behrens, 2008), they nevertheless presuppose a particular correct answer based on the external circumstances. One might consequently want to speak of externally guided decision-making in such a case.

In addition to such externally guided decision-making, instances of decision-making do exist for which there is no correct answer available for a subject based on external circumstances
(Goldberg and Podell, 1999, 2000; Lieberman and Eisenberger, 2005; Volz et al., 2006; Nakao et al., 2009b). Such decisions are usually made in the context of moral decision-making (e.g., Moll et al., 2006; Greene and Paxton, 2009) as well as in the context of preference judgment (Paulus and Frank, 2003; Johnson et al., 2005; Nakao et al., 2009a, 2010a,c), where the answer depends on the subject's own, i.e., internal, preferences rather than on external, i.e., circumstantial, criteria. One might consecutively want to speak of internally guided decision-making as distinguished from externally guided decision-making. Although subjects can draw on their representation of circumstantial criteria in externally guided decision-making, how and on what they can base their decision in internally guided decision-making remains unclear. More specifically, the neuronal and psychological mechanisms that guide decisions based on more internally oriented internal criteria in the absence of external ones remain unclear.

This study compares externally and internally guided decisionmaking in both respects: empirically and theoretically. First, we review the decision-making literature to clarify conceptual and 
operational differences between externally and internally guided decision-making. Regarding externally guided decision-making, we review reports of studies that have investigated the effect of a situation in which an objectively correct answer is difficult to predict (i.e., uncertain situation) because of insufficient information to make a judgment (e.g., probabilistic outcome). We also review the literature related to neuroeconomic studies using tasks in which the outcome is varied (or believed to be varied) by the other people's decisions. For internally guided decision-making, we review reports of studies of decision-making for which no correct answer exists, meaning that none of the stimuli or presented options is regarded as the only objectively correct answer.

Second, we compare externally and internally guided decisionmaking with regard to their recruitment of regions. For that we conducted a meta-analysis of previous neuroimaging studies using the multi-level kernel density analysis (MKDA) approach (Wager et al., 2007, 2009). Finally, based on the review of relating articles and results of the meta-analysis, we discuss the differences and commonalities between decision-making of these two kinds. We also discuss the possible directions to advance the future investigation, especially that of internally guided decision-making.

\section{REVIEW OF STUDIES OF DECISION-MAKING EXTERNALLY GUIDED DECISION-MAKING UNDER UNCERTAINTY Operational characteristics of externally guided decision-making under uncertainty}

Most experimental studies of decision-making have examined situations in which only one less-predictable correct answer exists. With low-predictability, a low probability of reward or punishment can be associated with a stimulus, action, and/or outcome. In such cases, decision-making can be characterized by "uncertainty." Platt and Huettel (2008) define the concept of uncertainty as the psychological state in which a decision maker lacks knowledge about what outcome will follow from either choice in decisionmaking. Experimentally, uncertainty has been operationalized as low-predictability using a probabilistic outcome (Volz et al., 2003, 2004, 2005; Delgado et al., 2005b; Knutson et al., 2005; Huettel, 2006; Tobler et al., 2007; Chandrasekhar et al., 2008; Preuschoff et al., 2008; Abler et al., 2009) or by a perceptual difficulty to judge (Heekeren et al., 2004; Grinband et al., 2006; Callan et al., 2009). Despite the low-predictability, these experimental situations subsume that one of the possible answers is correct. In these situations, participants must adjust their decision to comply with the externally defined sole correct answer.

For example, Volz et al. (2003) manipulated low-predictability by the probabilistic outcome. They examined brain activity during participants' prediction of which of the two concurrently presented visual stimuli would win. Each of the pairings of figures was associated systematically with a particular probability of winning from 60 to $100 \%$ (e.g., B wins against $\mathrm{C}$ with a mean probability of $60 \%)$. In their experiment, participants were never given explicit information about these probabilities.

As the manipulation of low-predictability, Hsu et al. (2005) manipulated the predictability of the probabilities of different outcomes. They compared neural substrates of decisionmaking under risk (low-predictability outcomes with predictable probabilities) and ambiguity (low-predictability outcomes with unpredictable probabilities) which are two conditions in which the consequences of possible outcomes have low-predictability.

Not only the probabilistic outcome, perceptual difficulty to judge is also used to manipulate uncertainty (Heekeren et al., 2004; Grinband et al., 2006; Callan et al., 2009; Banko et al., 2011). For example, Heekeren et al. (2004) used face and house stimuli to which were added several levels of noise to manipulate the amount of sensory evidence in the stimuli. Participants were asked to decide whether a presented image was a face or a house. Although an objectively correct answer was presented, it was difficult to predict which judgment (house or face) was correct for the stimulus during simultaneous presentation of noise.

Results of these neuroimaging reports using probabilistic outcome and perceptual difficulty have typically shown increased activity within the dorsal part of the medial prefrontal cortex (DMPFC; Volz et al., 2003, 2004; Hsu et al., 2005; Knutson et al., 2005; Grinband et al., 2006; Krain et al., 2006; Callan et al., 2009; Mohr et al., 2010a), lateral prefrontal cortex (LPFC; Volz et al., 2003, 2004; Heekeren et al., 2004; Hsu et al., 2005; Krain et al., 2006; Abler et al., 2009; Callan et al., 2009), orbitofrontal cortex (Hsu et al., 2005; Tobler et al., 2007; Abler et al., 2009), insula (Volz et al., 2003, 2004; Heekeren et al., 2004; Knutson et al., 2005; Grinband et al., 2006; Krain et al., 2006; Callan et al., 2009; Mohr et al., 2010a), and thalamus (Volz et al., 2003; Heekeren et al., 2004; Grinband et al., 2006; Krain et al., 2006; Callan et al., 2009; Mohr et al., 2010a).

\section{Theoretical accounting for externally guided decision-making under uncertainty}

The process of externally guided decision-making has generally been interpreted in the context of a reinforcement learning (RL) model. In that model, the expected value (i.e., the magnitude of outcome times the probability of outcome) biases the decision; the expected value is modified based on the prediction error (i.e., discrepancies between expected and actual rewards; e.g., O'Doherty et al., 2004; Tanaka et al., 2004; Kim et al., 2006; Yoshida and Ishii, 2006; Behrens et al., 2007; Cohen, 2007; Boorman et al., 2009; Glascher et al., 2009; Wunderlich et al., 2009).

Corresponding neural substrates to this model and related concepts have well been identified. The expected value is typically processed within the orbitofrontal cortex, amygdala, ventral striatum, and insula. Prediction error is related to the ventral striatum and the dorsal anterior cingulate cortex (dACC; Tanaka et al., 2004; Daw et al., 2006; Kim et al., 2006; Cohen, 2007; O’Doherty, 2007; Tom et al., 2007; Rolls et al., 2008; Glascher et al., 2009; Wunderlich et al., 2009, 2011).

Hampton et al. (2006) reported results suggesting an important limitation of the RL model. They sought to ascertain whether the use of stored knowledge of the task structure guides choice or whether learned values guide choice without assuming a higherorder structure, as in the standard RL model. A computational model of standard RL model and another model that exploits knowledge of a task structure for a probabilistic reversal learning task (i.e., when one action is "good" the other is "bad" and vice versa, as well as the rule that after a time the contingencies will reverse; structure-based model) were then constructed and fitted to both the behavioral and fMRI data. 
The results revealed that neural activity in the ventral region of MPFC (VMPFC), the orbitofrontal cortex and the posterior dorsal amygdala were more consistent with the expected reward signal from a structure-based model than with that from an RL model.

Their results imply that the standard RL model is not always appropriate for the analysis of decision-making in the human brain. The limitation of the standard RL model was also pointed out by other studies (Daw et al., 2006; Hampton et al., 2008; Pearson et al., 2011).

Taken together, externally guided decision-making under uncertainty has been investigated mainly using a task with a probabilistic outcome or stimuli with perceptually difficult judging. Although the RL model has generally been used to interpret externally guided decision-making, it is also pointed out that the model cannot fully explain the brain functions for externally guided decision-making under uncertainty.

\section{EXTERNALLY GUIDED DECISION-MAKING IN A SOCIAL SITUATION Operational characteristics of externally guided decision-making in a social situation}

In addition to the probabilistic outcome and perceptual difficulty, an outcome that is varied (or believed to be varied) by other people's decisions has been used in externally guided decisionmaking (e.g., trust game and prisoner's dilemma game; Rilling et al., 2002, 2004, 2008a; Delgado et al., 2005b; Elliott et al., 2006; Sanfey, 2007; Frith and Singer, 2008; McCabe and Castel, 2008; Assaf et al., 2009; Wischniewski et al., 2009; Yoshida et al., 2010). Despite low-predictability on a social basis, experimental situations include the presumption that one of the possible answers is correct, and participants are required to adjust their choices to comply with an externally defined single correct answer. For that, one might consequently want to categorize tasks of these kinds, called neuroeconomic tasks, as involving externally guided decision-making.

The study by Gallagher et al. (2002) is a good example of an externally guided decision-making in a social situation. They studied brain activation in humans who played the game rockscissors-paper against a human or a computer. The play of the "human" or the "computer" did not actually differ: they were random sequences.

In their experiment, greater activity was visible in the pregenual ACC (pACC) and MPFC when participants believed they were playing against a human as opposed to a computer. Similar observations have been obtained using neuroeconomic tasks of other kinds (prisoner's dilemma game, Rilling et al., 2004; guessing task, Elliott et al., 2006; domino game, Assaf et al., 2009; and a beauty contest game, Coricelli and Nagel, 2009).

\section{Theoretical accounts for externally guided decision-making in a social situation}

The control conditions of these experiments were non-social lowpredictability decision-making (e.g., random sequences of outcomes), meaning that the differences between conditions were not uncertainty itself but were differences in the stance of the participants (i.e., playing against a person, or against a computer). For that reason, the observed brain activities when participants believe they are playing against another person compared to the control task have been inferred as reflecting the process of thinking about the mental state of that person (mentalizing; Frith and Frith, 1999; Frith and Singer, 2008).

Hampton et al. (2008) presented evidence that mentalizing has the function of guiding decision-making during game performance. They scanned human participants using fMRI while they played a repetitive inspection game in which employees decide whether to work or shirk at each trial and an employer decides whether or not to inspect the work area. In addition to a simple RL model, the following two computational models were used to analyze the behavioral and fMRI data: a fictitious model, which exploits prediction of the opponent's next actions considering the history of prior actions by the opponent; and an influence model, which exploits not only tracking of the opponent's actions but which also incorporates knowledge of how one's own actions influence the opponent's strategy.

As a result, the influence model provided a better fit to participants' behavior than did either the fictitious model or the RL model. Regarding brain activity, results show that the expected reward signal from the influence model provides a better account of the neural data in MPFC than does that from a simple RL model. These results suggest that mentalizing engaged in MPFC affects reward prediction, and that it might be used to guide choice during game performance.

Collectively, these neuroeconomic researchers have examined the effects of social interaction in externally guided decisionmaking. Even if the outcome varied by other people's decisions, a correct answer is determined externally, and participants are required to predict which option produces a better outcome in each trial. Different from the externally guided decision-making under uncertainty, however, the results from these neuroeconomic studies do not reflect uncertainty itself, but instead reflect the effects of social interaction. These reports described that signals in MPFC related to mentalizing have a function of biasing decisionmaking in a social situation to choose an externally determined correct option.

\section{INTERNALLY GUIDED DECISION-MAKING}

\section{Operational characteristics of internally guided decision-making}

Uncertainty and social situations still presuppose some externally determined single correct answer, although that answer is chosen with low-predictability. How about the complete absence of one correct answer based on external circumstances, even when given no low-predictability choices? In such cases, we cannot rely on an externally determined objectively correct answer to choose and to regulate one's own behavior, and the answer and its correctness depends on one's own, i.e., internal, preferences rather than on circumstantial, i.e., external, criteria (Goldberg and Podell, 1999, 2000; Lieberman and Eisenberger, 2005; Volz et al., 2006; Nakao et al., 2009b).

Such situations are apparent in the context of moral decisionmaking (Moll et al., 2001, 2002, 2006; Zysset et al., 2002, 2003; Heekeren et al., 2003, 2005; Greene et al., 2004; Paulus and Frank, 2006; Schaich Borg et al., 2006; Greene and Paxton, 2009; Cikara et al., 2010; Hare et al., 2010; Sommer et al., 2010; Caspers et al., 2011; Kahane et al., 2011; Schleim et al., 2011). For instance, when requiring participants to decide about giving money to either 
themselves or to a charitable organization, the study by Moll et al. (2006) does not presume that either of the two options is correct. Here, the outcome indicating that the participant receives money (the good outcome in the case of the externally guided decisionmaking) is not necessarily a correct answer because, taking a more moral stance, the donation to the charitable organization might be regarded as the correct answer. While adopting the subject's viewpoint and that person's own financial interests, receiving the money (rather than giving it to charity) would be regarded as the correct answer. This choice entails that the decision (whether participant choose their behavior based on self-interest or moral) depends on criteria employed by the participant. Results demonstrate that costly decisions (choosing costly donation or costly opposition) were associated more closely with activation of the MPFC than pure reward decisions were.

A similar finding was also reported by Greene and Paxton (2009). They examined neural activity involved in participants' decisions of whether to tell the truth or lie when reporting their success at predicting the outcome of coin flips. In this task, if participants report their success at the prediction, then they win the amount of money shown. In contrast, if they report their failure at the prediction, they lose the amount of money shown. In this task, lying to get the money is not a good choice from a moral viewpoint. Nevertheless, reporting the successful prediction is a good choice for obtaining money even if it is based on lying. Consequently, neither of the choices was the correct answer. The authors found DMPFC, LPFC, and right parietal lobe activity when dishonest people chose to tell the truth instead of lying for profit.

In addition to such moral decision-making, preference judgments are included in internally guided decision-making. In the preference judgment task, participants are required to make a decision based on personal criteria; the judgment is not based on external criteria. Preference judgments of many kinds have been used in previous studies: preference judgment for food (Arana et al., 2003; Paulus and Frank, 2003; Hare et al., 2009; Piech et al., 2009; Linder et al., 2010), products (Knutson et al., 2007, 2008), brands (Santos et al., 2011), faces (Kim et al., 2007; Chen et al., 2010), holiday options (Chaudhry et al., 2009), paintings (Jarcho et al., 2011), political beliefs (Zamboni et al., 2009), occupations (Nakao et al., 2009a, 2010c), task types (Forstmann et al., 2006), agencies of choice (Forstmann et al., 2008), shapes (Jacobsen et al., 2006), and colors (Goldberg and Podell, 1999, 2000; Johnson et al., 2005).

For instance, Paulus and Frank (2003) investigated brain activity during preference judgment for soft drinks. They presented two pictures of a soft drink in each trial. In preference judgment tasks, participants were asked to judge which drink they would like better. In the control task (visual discrimination task), stimuli were the same picture set with the preference judgment task. Then they were asked to identify which soft drink was in a bottle, a can, or a carton: the control task has an objective correct answer with no uncertain situation.

Analogously, Nakao et al. (2009a) used an occupational choice task (e.g., Which occupation do you think you could do better? dancer or chemist) without an objectively correct answer and a word-length task (e.g., Which word is longer? - dentist or comedian) that has one certain correct answer. In the occupational choice task, participants were clearly instructed that there is neither an objectively correct answer nor a contingent outcome with each decision.

These preference judgment tasks typically show increased activity within the pACC, VMPFC, and posterior cingulate cortex (PCC) compared with the control task, which is the externally guided decision-making with a certain correct answer.

In sum, internally guided decision-making has been investigated in moral judgment and preference judgment studies. When compared with the judgment task with a clear objective correct answer, several neural substrates' increased activity has been observed during internally guided decision-making. Although MPFC seems to be observed consistently in internally guided decision-making (Nakao et al., 2009b, 2010b), no previous report has described examination of which brain regions were activated consistently among internally guided decisionmaking studies using a quantitative approach. Furthermore, no report has described a study that has investigated the differences and similarities of neural substrates between the two kinds of decision-making representing real-life decision-making (i.e., internally guided decision-making and externally guided decisionmaking under uncertainty). For that purpose, we conducted the exploratory meta-analysis described hereinafter.

\section{METHOD}

\section{STUDY SELECTION}

Research papers were found primarily by searching the PubMed database (http://www.ncbi.nlm.nih.gov/pubmed/) using the keywords ("fMRI" or "functional magnetic resonance imaging" or "PET" or "positron emission tomography") and ("decisionmaking") and ("uncertain" or "uncertainty" or "probability" or "probabilistic" or "difficult" or "difficulty" or "neuroeconomic" or "economic" or "social" or "game" or "moral" or "morality" or "ethic" or "ethical" or "preference" or "prefer" or "belief" or "free" or "evaluation") As additional references, we added several reports from the reference lists of the relevant articles to ensure the inclusion of all relevant studies fitting our criteria. The reference lists of several review articles were also inspected (Frith and Frith, 1999; Bechara et al., 2000; Rolls, 2000, 2004; Greene and Haidt, 2002; Casebeer, 2003; Greene, 2003; Fellows, 2004; Glimcher and Rustichini, 2004; O’Doherty, 2004, 2007; Sanfey and Cohen, 2004; Moll et al., 2005; Roberts, 2006; Sanfey et al., 2006; Volz et al., 2006; Coricelli et al., 2007; Sanfey, 2007; Wallis, 2007; Frith and Singer, 2008; Heekeren et al., 2008; Lee, 2008; Platt and Huettel, 2008; Rangel et al., 2008; Rilling et al., 2008b; Rolls and Grabenhorst, 2008; Rushworth and Behrens, 2008; Sanfey and Chang, 2008; Vorhold, 2008; Knabb et al., 2009; Volz and von Cramon, 2009; Wischniewski et al., 2009; Balleine and O’Doherty, 2010; Mohr et al., 2010a,b; Nakao et al., 2010b; Rangel and Hare, 2010; Liu et al., 2011).

In the relevant literature, we included reports of studies of decision-making of the following kinds (see also Table 1). (1) Brain activity coordinates from healthy participants were included. Those of neurological or psychiatric patients and those using medications were not included. (2) Only reports describing all the significant activation foci as $3 \mathrm{D}$ coordinates $(x, y, z)$ in the space of the MNI template or the atlas of Talairach and Tournoux were included; those of studies based on region of interest (ROI) 
Table 1 | Summary of inclusion and exclusion criteria for meta-analysis

\begin{tabular}{|c|c|c|}
\hline & Inclusion & Exclusion \\
\hline \multirow[t]{5}{*}{$\begin{array}{l}\text { For all decision- } \\
\text { making studies }\end{array}$} & - Brain activity coordinates from healthy participants & $\begin{array}{l}\text { - Brain activity coordinates from neurological or } \\
\text { psychiatric patients and those using medication }\end{array}$ \\
\hline & $\begin{array}{l}\text { - Reports describing all significant activation foci as 3D coordinates ( } x, y, z) \\
\text { in the space of the MNI template or the atlas of Talairach and Tournoux }\end{array}$ & - Studies based on region of interest (ROI) analysis \\
\hline & $\begin{array}{l}\text { - Data related to brain activity revealed by task comparison or image } \\
\text { subtraction methods, parametric designs, or brain-behavioral correction }\end{array}$ & $\begin{array}{l}\text { - Data related to changes in functional or effective } \\
\text { connectivity }\end{array}$ \\
\hline & - Activation data & - Deactivation data \\
\hline & - Studies using a task requiring a participant to make a decision & $\begin{array}{l}\text { - Studies using a task requiring no participant to make } \\
\text { a decision }\end{array}$ \\
\hline \multirow[t]{2}{*}{$\begin{array}{l}\text { Externally guided } \\
\text { decision-making }\end{array}$} & $\begin{array}{l}\text { - Studies using a task for which one choice is associated with a better } \\
\text { outcome (e.g. reward) than others, indicating that the choice is correct }\end{array}$ & $\begin{array}{l}\text { - Studies using a computational model that is not } \\
\text { applicable to internally guided decision-making to } \\
\text { analyze fMRI data }\end{array}$ \\
\hline & $\begin{array}{l}\text { - Studies using a task for which no feedback was presented but for which } \\
\text { the task has one objective correct answer and participants had to try to } \\
\text { respond correctly }\end{array}$ & $\begin{array}{l}\text { - Neural activations specific to the feedback epoch } \\
\text { and prediction error }\end{array}$ \\
\hline Under uncertainty & $\begin{array}{l}\text { - Studies investigating the effect of a situation in which it is difficult to } \\
\text { predict a correct answer because of insufficient information to judge } \\
\text { (e.g., low probability of reward > high probability of reward) }\end{array}$ & $\begin{array}{l}\text { - Contrasts investigating the effect of risk or expected } \\
\text { value in the case that these were manipulated not } \\
\text { only by the probability of an outcome but also by } \\
\text { the amount of the outcome }\end{array}$ \\
\hline In social situation & $\begin{array}{l}\text { - Reports of studies investigating a brain region that is sensitive to varied } \\
\text { outcomes by other people's decisions (e.g., Low predictable } \\
\text { (social) > Low predictable (nonsocial)) }\end{array}$ & $\begin{array}{l}\text { - Contrasts investigating the effect from which } \\
\text { different decisions were excluded (e.g., share vs. } \\
\text { keep decisions in a trust game) }\end{array}$ \\
\hline \multirow[t]{3}{*}{$\begin{array}{l}\text { Internally guided } \\
\text { decision-making }\end{array}$} & $\begin{array}{l}\text { - Studies using tasks in which no stimulus or option was regarded as } \\
\text { correct }\end{array}$ & $\begin{array}{l}\text { - Contrasts comparing internally guided } \\
\text { decision-making of different kinds }\end{array}$ \\
\hline & $\begin{array}{l}\text { - Studies investigating differences of decision-making for problems with no } \\
\text { correct answer from decision-making for problems with one correct } \\
\text { answer }\end{array}$ & $\begin{array}{l}\text { - Contrasts comparing different decisions in internally } \\
\text { guided decision-making }\end{array}$ \\
\hline & & $\begin{array}{l}\text { - Study using a task which clearly requires } \\
\text { participants to make a judgment based on social } \\
\text { criteria instead of a participant's own criteria }\end{array}$ \\
\hline
\end{tabular}

analysis were excluded. (3) Data related to brain activity revealed by task comparison or image-subtraction methods, parametric designs, or brain-behavioral correction were included. Data related to changes in functional or effective connectivity were excluded. (4) Only activation data were included in the relevant analysis; deactivation data were not considered. (5) A study was regarded as decision-making-related if it necessitated that a participant make a decision. We therefore excluded all studies in which participants were not required to make a decision.

In the review part of this paper, we cited possible related articles. For our meta-analysis, however, we selected the articles more strictly for comparison between externally and internally guided decision-making. In numerous externally guided decisionmaking studies, psychological/computational models (e.g., RL model) and related concepts (e.g., expected value and prediction error) have been used broadly (e.g., Hampton et al., 2006; Cohen, 2007). Although these models and concepts presuppose the presence of outcomes, internally guided decision-making did not presuppose the presence of an outcome (i.e., an objectively correct answer): these models and concepts used in externally guided decision-making were not applicable to internally guided decision-making. This difference makes it difficult to use the results obtained using models and concepts of these kinds for comparisons between externally guided decision-making and internally guided decision-making. For that reason, in the analyses presented herein, we did not include reports of studies of externally guided decision-making based on these models and concepts. We chose externally guided decision-making studies that focused on the effect from the situation with uncertainty or with social interaction (e.g., low-predictability vs. high-predictability for externally guided decision-making under uncertainty; low-predictability in a social situation vs. low-predictability in a non-social situation for externally guided decision-making in a social situation).

Similarly, as representative of internally guided decisionmaking, we chose studies which specifically addressed the effect from a situation without an externally determined correct answer (no objective correct answer vs. a single objective correct answer).

See the following and Table $\mathbf{1}$ for details related to inclusion and exclusion criteria.

\section{Externally guided decision-making}

As externally guided decision-making studies, we included reports of studies using a task in which one choice was associated with a better outcome (e.g., reward) than others, indicating that the 
choice is correct. We also included studies using a task in which no feedback was presented, but for which the task has one objective correct answer and participants had to try to respond correctly (e.g., Heekeren et al., 2004; Hsu et al., 2005; Callan et al., 2009; Banko et al., 2011). For comparison with internally guided decision-making, we excluded reports of studies using a computational model that is not applicable to internally guided decision-making to analyze the fMRI data (e.g., RL model with incorporating the effect of the situation of low-predictability (task structure; Hampton et al., 2006, see review part for the details). We excluded neural activations that are specific to the feedback epoch and prediction error (e.g., Wittmann et al., 2008), which cannot be compared with internally guided decision-making.

Externally guided decision-making under uncertainty. As reports of studies of externally guided decision-making under uncertainty we included those of studies which investigated the effect of a situation in which it is difficult to predict a correct answer because of the insufficient information for judgment (e.g., low probability of reward $>$ high probability of reward). Contrasts that investigated the effect of risk (e.g., Cohen, 2007; Xue et al., 2009; Van Leijenhorst et al., 2010) or expected value (e.g., Rolls et al., 2008; Symmonds et al., 2010; Wu et al., 2011b) were excluded in cases where these were manipulated not only by the probability of outcome but also by the amount of outcome. We excluded them because our main interest here is not the effect of the amount of the outcome but the effect from a low-predictability (i.e., uncertain) situation (for results of a meta-analysis of reward/outcome-related brain regions, see Liu et al., 2011; for results of meta-analysis of risk-related brain regions, see Mohr et al., 2010a).

Externally guided decision-making in a social situation. With studies of externally guided decision-making in a social situation, we included reports of studies that investigated a brain region that is sensitive to the varied outcome by other people's decisions [e.g., low-predictability (social) > low-predictability (nonsocial)]. Contrasts that investigated the effects from different decisions were excluded (e.g., share vs. keep decisions in a trust game as described by Delgado et al., 2005a).

\section{Internally guided decision-making}

For studies of internally guided decision-making, we included studies using tasks in which no stimulus or option was regarded as correct. Studies investigating differences of decision-making for problems with no correct answer from decision-making for problems with one correct answer were included. We excluded the contrasts which compared different kinds of internally guided decision-making (e.g., Schaich Borg et al., 2006; Hare et al., 2009; Sommer et al., 2010). We also did not include contrasts which compared different decisions in the internally guided decision-making (e.g., Sanfey et al., 2003; Greene et al., 2004). We excluded a study using a task that clearly requires participants to make judgments based on social criteria instead of the participants' own criteria (Prehn et al., 2008).

ANALYSIS TO EVALUATE THE BALANCE BETWEEN SELECTED STUDIES

To evaluate stimulus-specific effects in the comparison between externally and internally guided decision-making, the stimulus types (verbal/non-verbal or visual/auditory) of these studies were described respectively for these studies of decision-making (see Table A1 in Appendix). Chi-square tests or Fisher's exact tests were conducted to examine whether the constitution of studies relying upon stimuli of different types differs between externally and internally guided decision-making. Because MKDA results are also affected by the sample size and the quality of the statistical analysis of the original studies, studies in these categories were also compared relative to their sample size and the false discovery rate correction they adopted.

Furthermore, to assess the influence of difficulty of the experimental tasks on the meta-analysis, the response time differences between the compared conditions were calculated (e.g., uncertain - control conditions, preference judgment - control condition; see Table A1 in Appendix). In cases where parametric design (e.g., decreasing predictability, 50\% > 69\% > 100\%) was used, we took the average of all the differences between close conditions (e.g., average between 50-69 and 69-100\%). In several studies, the exact differences of reaction times were not available, although the results of statistical analyses were available. To take account of these cases, we conducted a Chi-square test using data showing whether the reaction times of the experimental condition (uncertain or internally guided) were significantly longer than those of the control condition or not.

\section{MULTI-LEVEL KERNEL DENSITY ANALYSIS}

We conducted MKDA (Wager et al., 2007, 2009), a coordinatebased meta-analysis method, for peak coordinates in a particular statistical contrast map (SCM) of the selected decision-making studies. In this method, the probability of activation of a given voxel in the brain across the studies is estimated. The null hypothesis is a random distribution of peak coordinates within each comparison in the standard brain. The well-established MKDA approach (Wager et al., 2007, 2009) has been used in several studies (Etkin and Wager, 2007; Kober et al., 2008; Wang et al., 2010; Fan et al., 2011; Qin and Northoff, 2011). The MKDA method was selected because of its several important advantages over the meta-analysis approaches used previously (ALE, KDA). First, the previous methods analyzed the peak coordinates from a set of studies without considering the nesting of peaks within contrasts. Such procedures produce results that are biased by numerous peak coordinates reported in a single study. In the MKDA approach, multiple peaks are nested within a contrast, and multiple contrasts are nested within a study. This method enables true assessment of consistency across studies. A second advantage is that MKDA allows the weighting of contrasts by study sample size and by the quality of analyses based on random or fixed-effects designs used in the original study. These weights allow for studies with more numerous participants. Alternatively, random effects designs are assigned greater weight to exert more influence on the meta-analytic results. Finally, the results from MKDA provide a straightforward interpretation as a weighted proportion of activated contrasts within a kernel around (typically $10 \mathrm{~mm}$ of) each voxel (Kober et al., 2008).

For the present meta-analysis, relevant variables were sample size, analysis type (fixed or random effects), and coordinates of peak activation in selected contrast of previous studies. The coordinates in Talairach space were translated into MNI space. The 
coordinates from the one contrast were used to build one special SCM, and the coordinates from each SCM were convolved with a spherical kernel of $10 \mathrm{~mm}$ radius. The voxels within $10 \mathrm{~mm}$ around the coordinate were thresholded at a maximum value of 1 . The SCM were then weighted by the sample size and the analysis type (fixed or random effects). The weight for each contrast was the square root of the sample size, multiplied by an adjustment weight for the analysis type ( 1 for the resulted from a randomeffect analysis; 0.75 for the results from a fixed-effects analysis). We did not consider the $Z$-scores of each study because they are not provided by all studies we selected. In addition, their inclusion has been shown to affect the replicability of activation across studies, thereby rendering interpretation more difficult (Kober et al., 2008; Wager et al., 2009). A statistical threshold was established through 5000 iterations of a Monte Carlo procedure. The results were reported as an MKDA statistic map at a height threshold of familywise error rate (FWE) corrected at $p<0.05$, a stringent threshold of FWE corrected for spatial extent at $p<0.05$ with primary thresholds of uncorrected $p<0.001$, and a medium threshold of FWE corrected for spatial extent at $p<0.05$ with primary thresholds of uncorrected $p<0.01$.

To compare the differences and similarities between externally and internally guided decision-making, we conducted the metaanalysis in two steps. First, we conducted the meta-analysis for decision-making of each kind [i.e., externally guided decisionmaking (uncertainty), externally guided decision-making (social), and internally guided decision-making]: separate MKDA statistic maps were constructed for decision-making of each kind. Two of these maps were mounted on the same standard brain to indicate the distinctive regions involved in these instances of decision-making. Inclusive masks were applied to determine the overlap between two of these activation maps (i.e., externally guided decision-making (uncertainty) and internally guided decision-making, or externally guided decision-making (social) and internally guided decision-making). The overlap analyses were conducted using MRIcroN (Rorden, 2007).

Second, we compared the activation of externally guided decision-making (uncertainty) and internally guided decisionmaking by subtraction analysis in MKDA: separate maps constructed for decision-making of each of the two types were subtracted to yield difference maps. The same procedure was employed in the course of the Monte Carlo randomization to establish a threshold for significant differences. We did not construct difference maps between externally guided decision-making (social) and internally guided decision-making, or between externally guided decision-making (social) and externally guided decision-making (uncertainty) because only six studies were included for externally guided decision-making (social).

\section{RESULTS \\ BALANCE BETWEEN THE SELECTED STUDIES FOR EACH DECISION-MAKING}

Of the studies considered, 18 studies (24 contrasts, 205 coordinates, 293 participants in total) were regarded as relevant for externally guided decision-making (uncertainty), 6 studies (8 contrasts, 49 coordinates, 86 participants) were included for externally guided decision-making (social), and 18 studies were selected for internally guided decision-making (22 contrasts, 143 coordinates, 303 participants; see Table A1 in Appendix). Chisquare tests show a significant difference for the number of studies among these three categories $\left[\chi^{2}(2)=6.86, p=0.03\right]$. Post hoc Bonferroni tests $(p<0.05)$ revealed no significant difference between externally guided decision-making (uncertainty) and internally guided decision-making. The studies of externally guided decision-making (social) were fewer than those of externally guided decision-making (uncertainty) and internally guided decision-making. Because of the low number of externally guided decision-making (social), we did not use the dataset for externally guided decision-making (social) to construct difference maps [i.e., externally guided decision-making (uncertainty) vs. externally guided decision-making (social), and externally guided decision-making (social) vs. internally guided decision-making] in the following MKDA analysis.

Regarding externally guided decision-making (uncertainty) and internally guided decision-making, Fisher's exact test revealed no significant difference related to the stimulus modality (visual or auditory; $p=1.00$ ). Moreover, no significant difference was found related to the quality of statistics [corrected or uncorrected; $\left.\chi^{2}(1)=1.78, p=0.18\right]$, and the sample size $[t(34)=0.20$, $p=0.84]$. No significant difference of the sample size was observed even when we included externally guided decision-making [social; $F(2,39)=0.24, p=0.79$ ]. A significant difference was found related to the proportion of verbal stimulus and non-verbal stimulus (Fisher's exact test $p<0.01$ ). Verbal stimuli tended to be used more in internally guided decision-making; non-verbal stimuli were used more in externally guided decision-making under uncertainty (see Table A1 in Appendix).

Furthermore, to assess the influence of difficulty of the experimental tasks on the meta-analysis, the response time differences between the compared conditions (e.g., uncertain - control, or internally guided - control) were calculated. No significant difference of the reaction-time differences was observed between externally guided decision-making (uncertainty) and internally guided decision-making $[t(24)=1.18, p=0.25]$. No significant difference was observed even when we included externally guided decision-making in social situations $[F(2,25)=1.91, p=0.17]$. Consistently, no significant difference was found related to the statistical difference of reaction times (significantly longer in experimental condition or not) between externally guided decisionmaking (uncertainty) and internally guided decision-making $\left[\chi^{2}(1)=0.27, p=0.60\right]$.

To assess whether the experimental conditions (uncertain, social, or internally guided) induced a longer time to make a decision than the control condition, we compared the reactiontime differences with 0 (no difference of reaction time between the conditions) within each type of decision-making. No significant difference was observed in any type of decision-making [externally guided (uncertainty), Welch's $t(8)=0.50, p=0.63$; externally guided (social), Welch's $t(1)=1.47, p=0.38$; internally guided, Welch's $t(16)=1.31, p=0.21]$. Consistent with these results, Chi-square tests for the statistical difference of reaction times (significantly longer in experimental condition or not) revealed no significant differences in externally guided [uncertainty, $\left.\chi^{2}(1)=1, p=0.32\right]$ and in internally guided $\left[\chi^{2}(1)=0.07\right.$, 
$p=0.80]$. Because of the small sample size, we were unable to use Chi-square tests for externally guided decision-making (social).

\section{MKDA RESULTS \\ Externally guided decision-making (uncertainty) vs. internally guided decision-making}

Meta-analysis results indicated different neural representation patterns for externally guided decision-making (uncertainty; Figure 1A) and internally guided decision-making (Figure 1C; see also Table 2). Figure 2A presents results of statistical overlap as based on inclusive masking. Regions with significant proportions of activation for the externally guided decision-making were in DMPFC, dorsal LPFC (DLPFC), insula, thalamus, and IPL. For internally guided decision-making, the clusters in MPFC, pACC, PCC, and superior temporal gyrus (STG) were revealed. Only the DMPFC (BA 8) overlapped between decision-making of the two kinds. Although we refer to the overlapped region as DMPFC hereinafter, it is noteworthy that the same region (BA8) has been mentioned also as a part of the supplemental motor area (SMA; Caria et al., 2011) and pre-SMA (Rubia et al., 2001; Chen et al., 2010) in several previous studies.
Figure 3 presents results from the two difference maps as based on their respective contrasts [i.e., externally guided decisionmaking (uncertainty) $</>$ internally guided decision-making]. Although the extensions of the several clusters were restricted, the direct comparison showed (more or less) similar regions to those portrayed in Figure 1. Internally guided decision-making showed larger clusters in mainly medial cortical regions while externally guided decision-making showed stronger clusters in lateral regions (see also Table 3 ).

\section{Externally guided decision-making (social) vs. internally guided decision-making}

Figure 1B presents results of externally guided decision-making in a social situation. To observe the effect from social component included in internally guided decision-making, we mounted the MKDA results of externally guided decision-making (social) and internally guided decision-making on the same stereotaxic standard brain, and indicated the statistical overlaps (Figure 2B. DMPFC $(B A 8,9)$ overlapped between social and internally guided decision-making. In contrast, no overlap was observed in the other regions observed in internally guided decision-making.

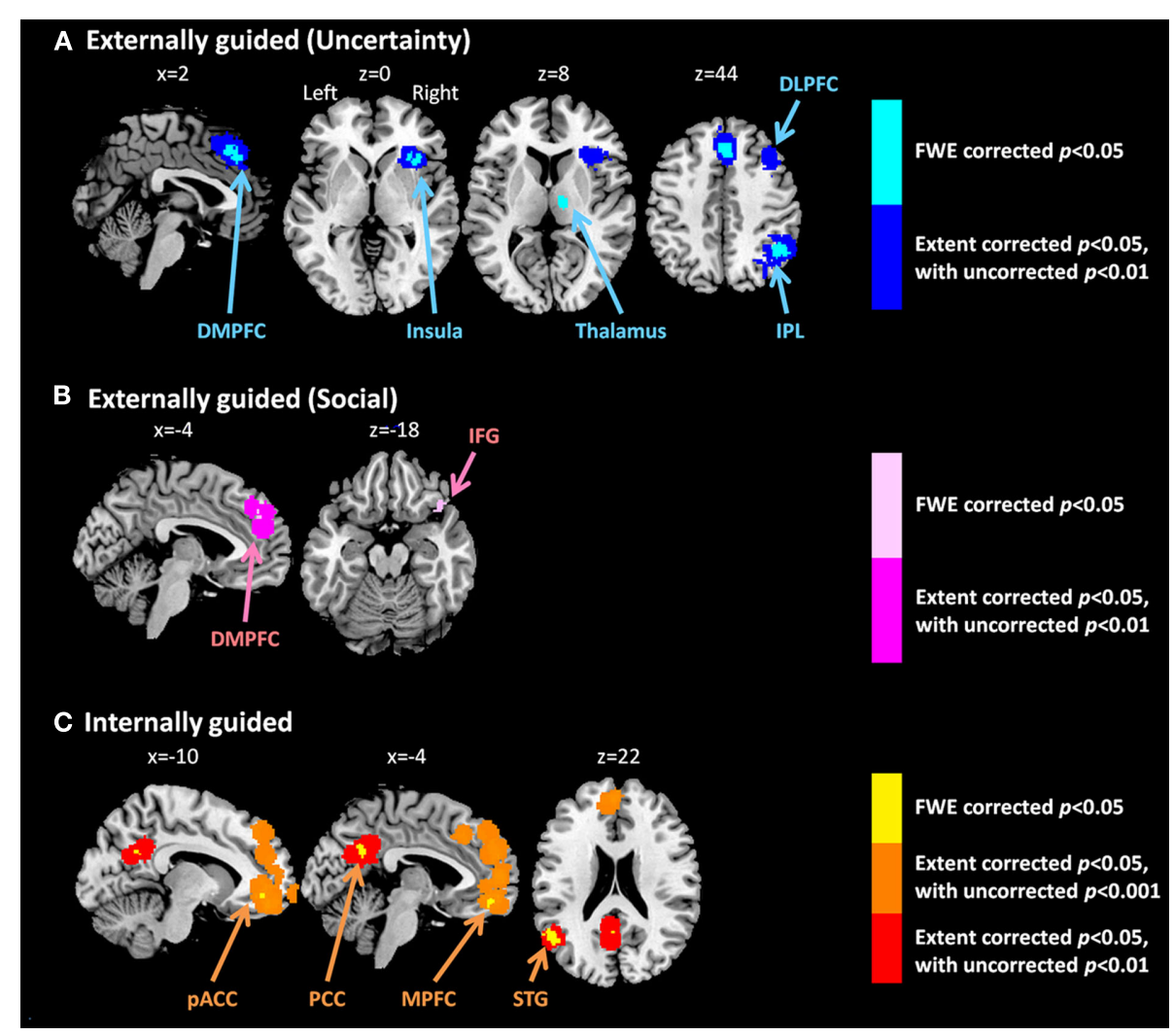

FIGURE 1 | Multi-level kernel density analysis results for (A) externally guided decision-making under uncertainty, (B) externally guided decision-making in a social situation, and $(C)$ internally guided decision-making. Results from the different statistical thresholds are shown with different colors: cyan, pink, and yellow, a height threshold of familywise error rate (FWE) corrected at $p<0.05$; orange, a stringent threshold of FWE corrected for the spatial extent at $p<0.05$ with primary thresholds of uncorrected $p<0.001$; blue, violet, and red, a medium threshold of FWE corrected for the spatial extent at $p<0.05$ with primary thresholds of uncorrected $p<0.01$. No clusters were identified at the stringent threshold in externally guided decision-making under uncertainty or in a social situation. DMPFC, dorsomedial prefrontal cortex; DLPFC, dorsolateral prefrontal cortex; IPL, inferior parietal lobule; IFG, inferior frontal gyrus; pACC, perigenual anterior cingulate cortex; PCC, posterior cingulate cortex; MPFC, medial prefrontal cortex.; STG, superior temporal gyrus. 
Table 2 | MKDA results for decision-making studies of each type.

\begin{tabular}{|c|c|c|c|c|c|c|c|}
\hline \multirow[t]{2}{*}{ Type of decision-making } & \multirow[t]{2}{*}{ Region } & \multirow[t]{2}{*}{ BA } & \multicolumn{3}{|c|}{ MNI coordinates } & \multirow[t]{2}{*}{ Voxels } & \multirow[t]{2}{*}{ Maxstat. } \\
\hline & & & $\boldsymbol{x}$ & $y$ & $z$ & & \\
\hline \multirow[t]{5}{*}{ Externally guided (Uncertainty) } & Dorsomedial prefrontal cortex (DMPFC) & 8,6 & 2 & 28 & 44 & 149 & $0.34^{* *}$ \\
\hline & Dorsolateral prefrontal cortex (DLPFC) & 9,8 & 40 & 24 & 38 & 966 & $0.23^{\dagger}$ \\
\hline & Insula & 47 & 34 & 20 & 0 & 150 & $0.37 * *$ \\
\hline & Thalamus & $\mathrm{N} / \mathrm{A}$ & 12 & -14 & 8 & 77 & $0.26^{* *}$ \\
\hline & Inferior Parietal Lobule (IPL) & 40 & 48 & -54 & 42 & 134 & $0.34^{* *}$ \\
\hline \multirow[t]{4}{*}{ Externally guided (Social) } & Dorsomedial prefrontal cortex (DMPFC) & 9 & 4 & 50 & 22 & 11 & $0.48 * *$ \\
\hline & & $9,8,6$ & -4 & 46 & 30 & 1156 & $0.38^{\dagger}$ \\
\hline & & 9 & -6 & 44 & 36 & 12 & $0.48 * *$ \\
\hline & Inferior frontal gyrus (IFG) & 47 & 42 & 22 & -18 & 38 & $0.5^{* *}$ \\
\hline \multirow[t]{4}{*}{ Internally guided } & Medial prefrontal cortex (MPFC) & $10,11,6,8,9,32$ & -2 & 50 & 14 & 4983 & $0.21^{*}$ \\
\hline & Perigenual anterior cingulate cortex (pACC) & 32 & -10 & 44 & -8 & 14 & $0.21 * *$ \\
\hline & Posterior cingulate cortex (PCC) & 31 & -4 & -56 & 28 & 64 & $0.32 * *$ \\
\hline & Superior temporal gyrus (STG) & 39 & -50 & -60 & 22 & 64 & $0.3^{* *}$ \\
\hline
\end{tabular}

Regions marked ** were significant at FWE voxel-level corrected $p<0.05$ with extent size $>10$ voxels. Regions marked * were significant at FEW extent corrected

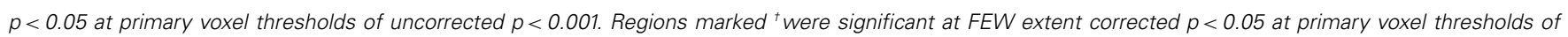

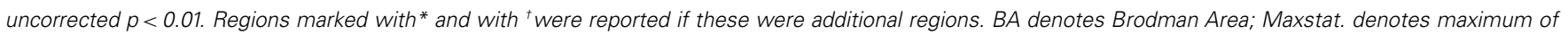
the $Z$ field.

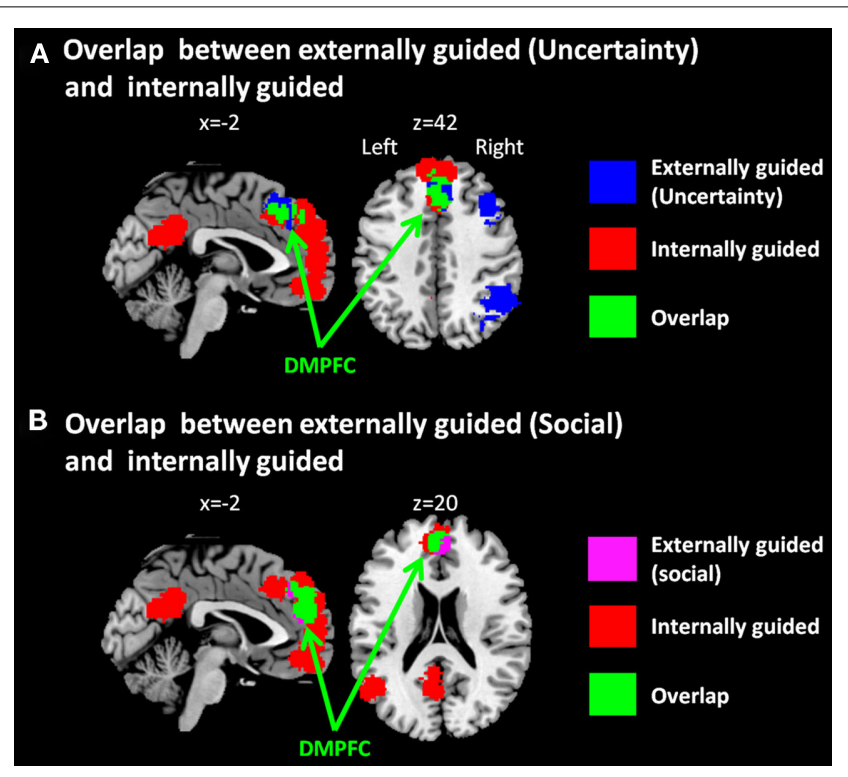

FIGURE 2 | Multi-level kernel density analysis results for overlaps (A) between externally guided decision-making under uncertainty and internally guided decision-making and $(B)$ between externally guided decision-making in a social situation and internally guided decision-making. DMPFC, dorsomedial prefrontal cortex.

\section{DISCUSSION}

OPERATIONAL DIFFERENCES BETWEEN EXTERNALLY AND INTERNALLY GUIDED DECISION-MAKING

As we described earlier in the review part, experimentaloperational differences existed between externally and internally guided decision-making. Externally guided decision-making studies have used the decision-making task with a single correct answer that is less-predictable. In these situations, participants must adjust their decision to comply with the externally defined single correct answer. Uncertainty (i.e., low-predictability) has been manipulated with a probabilistic outcome or with stimuli that are perceptually difficult to judge. In studies of externally guided decision-making in a social situation, an outcome that is varied (or which was believed to be varied) by other people's decisions has been used.

In contrast with such externally guided decision-making, in internally guided decision-making, no correct answer based on external circumstances is available for the subject. Studies of such decision-making have been used for moral judgment and preference judgment tasks for which the answer depends on the subject's own, i.e., internal, preferences rather than on external, i.e., circumstantial, criteria (see Figure $\mathbf{4}$ for a summary of the difference between externally and internally guided decision-making).

\section{NEURAL DIFFERENCES BETWEEN EXTERNALLY AND INTERNALLY GUIDED DECISION-MAKING}

Our meta-analysis indicated that different neural networks were recruited for externally guided decision-making (uncertainty) and internally guided decision-making. The DMPFC-DLPFC-insulathalamus-IPL network was activated consistently in externally guided decision-making under uncertainty (see Figures 1A and 3A). This result was consistent with the results of previous metaanalysis study about risky decision-making (Mohr et al., 2010a), which confirms that the method used here works properly and that it produces reliable results.

In internally guided decision-making, MPFC-pACC-PCCSTG network was activated consistently (see Figure 1C). Even when we compared externally guided decision-making under 


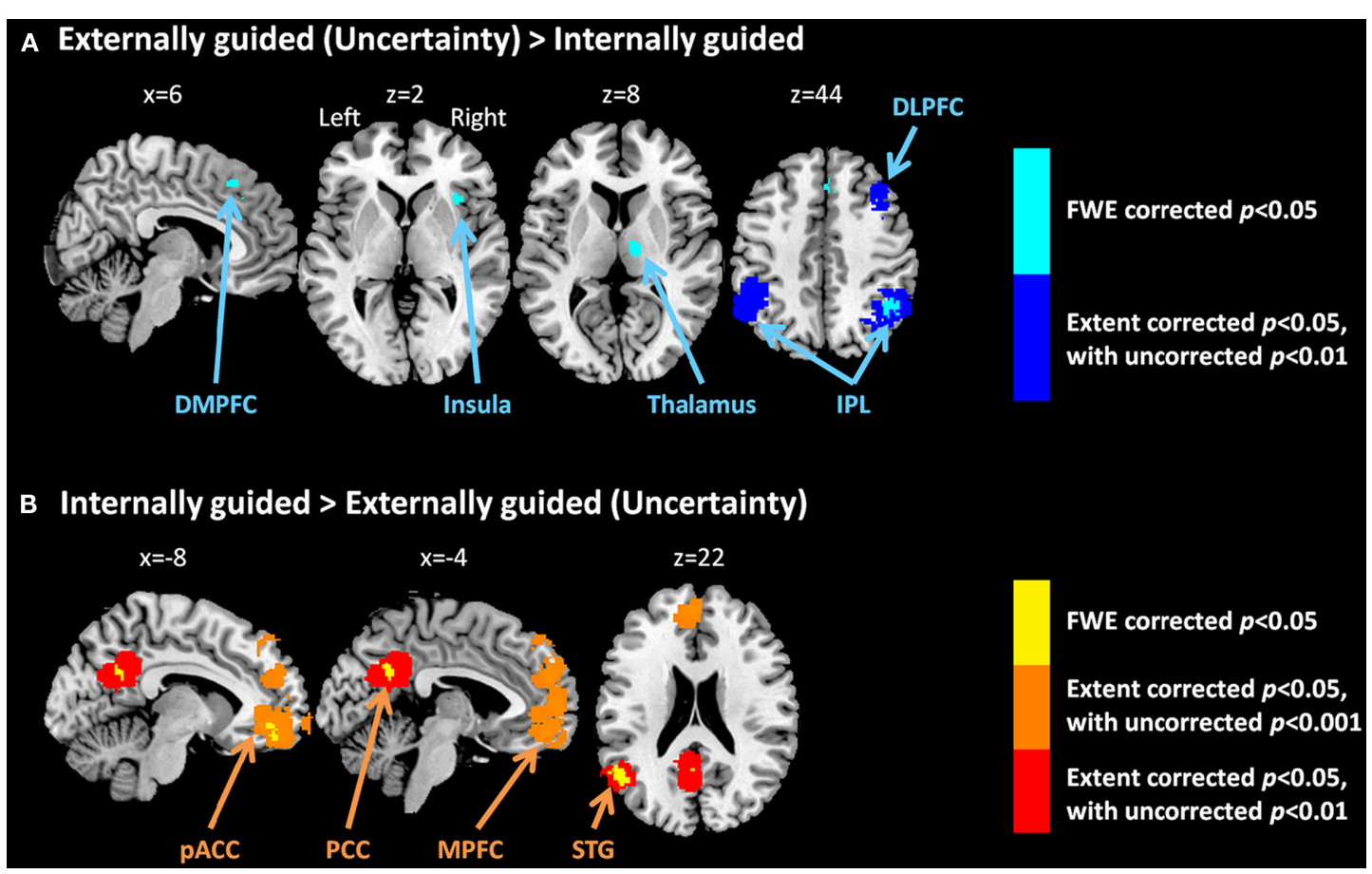

FIGURE 3 | Multi-level kernel density analysis results from the difference maps for (A) externally guided decision-making under uncertainty > internally guided decision, and for (B) internally guided decision-making > externally guided decision under uncertainty. Results from the different statistical thresholds are shown with different colors: cyan, pink, and yellow, a height threshold of familywise error rate (FWE) corrected at $p<0.05$; orange, a stringent threshold of FWE corrected for spatial extent at $p<0.05$ with primary thresholds of uncorrected $p<0.001$; blue, violet, and red, a medium threshold of FWE corrected for spatial extent at $p<0.05$ with primary thresholds of uncorrected $p<0.01$. No cluster was observed at the stringent threshold in externally guided decision-making under uncertainty $>$ internally guided decision-making. DMPFC, dorsomedial prefrontal cortex; DLPFC, dorsolateral prefrontal cortex; IPL, inferior parietal lobule; $\mathrm{PACC}$, perigenual anterior cingulate cortex; PCC, posterior cingulate cortex; MPFC, medial prefrontal cortex; STG, superior temporal gyrus.

Table 3 | MKDA results from the difference map between internally and externally guided decision-making (uncertainty).

\begin{tabular}{|c|c|c|c|c|c|c|c|}
\hline \multirow[t]{2}{*}{ Contrasts } & \multirow[t]{2}{*}{ Region } & \multirow[t]{2}{*}{ BA } & \multicolumn{3}{|c|}{ MNl coordinates } & \multirow[t]{2}{*}{ Voxels } & \multirow[t]{2}{*}{ Maxstat. } \\
\hline & & & $\boldsymbol{x}$ & $y$ & $z$ & & \\
\hline \multirow[t]{6}{*}{ Externally guided (Uncertainty), > internally guided } & Dorsomedial prefrontal cortex (DMPFC) & 8 & 6 & 26 & 48 & 47 & $0.3^{* *}$ \\
\hline & Dorsolateral prefrontal cortex (DLPFC) & 9,8 & 40 & 24 & 38 & 1010 & $0.23^{\dagger}$ \\
\hline & Insula & 13 & 36 & 18 & 2 & 17 & $0.32 * *$ \\
\hline & Thalamus & N/A & 12 & -14 & 8 & 77 & $0.26 * *$ \\
\hline & Inferior parietal lobule (IPL) & 40 & 46 & -52 & 42 & 73 & $0.34^{* *}$ \\
\hline & & 40 & -48 & -48 & 44 & 849 & $0.22^{\dagger}$ \\
\hline \multirow[t]{4}{*}{ Internally guided, > externally guided (Uncertainty) } & Medial prefrontal cortex (MPFC) & $10,11,32,9,8$ & -2 & 52 & 8 & 3354 & $0.2^{*}$ \\
\hline & Perigenual anterior cingulate cortex (pACC) & 11,32 & -8 & 48 & -12 & 32 & $0.21^{* *}$ \\
\hline & Posterior cingulate cortex (PCC) & 31 & -4 & -56 & 28 & 64 & $0.32^{* *}$ \\
\hline & Superior temporal gyrus (STG) & 39 & -50 & -60 & 22 & 65 & $0.3^{* *}$ \\
\hline
\end{tabular}

Regions marked ** were significant at FWE voxel-level corrected $p<0.05$ with extent size $>10$ voxels.

Regions marked *were significant at FEW extent corrected $p<0.05$ at primary voxel thresholds of uncorrected $p<0.001$

Regions marked ${ }^{\dagger}$ were significant at FEW extent corrected $p<0.05$ at primary voxel thresholds of uncorrected $p<0.01$.

Regions marked with ${ }^{*}$ and with ${ }^{\dagger}$ were reported if these were additional regions.

BA denotes Brodman Area; Maxstat. denotes the maximum of the Z field.

uncertainty and internally guided decision-making directly, the same networks remained for each category of decision-making (see Figure 3B).
The only common region between these two was DMPFC (Figure 2A), which was broader in comparison of externally guided decision-making in a social situation and internally guided 


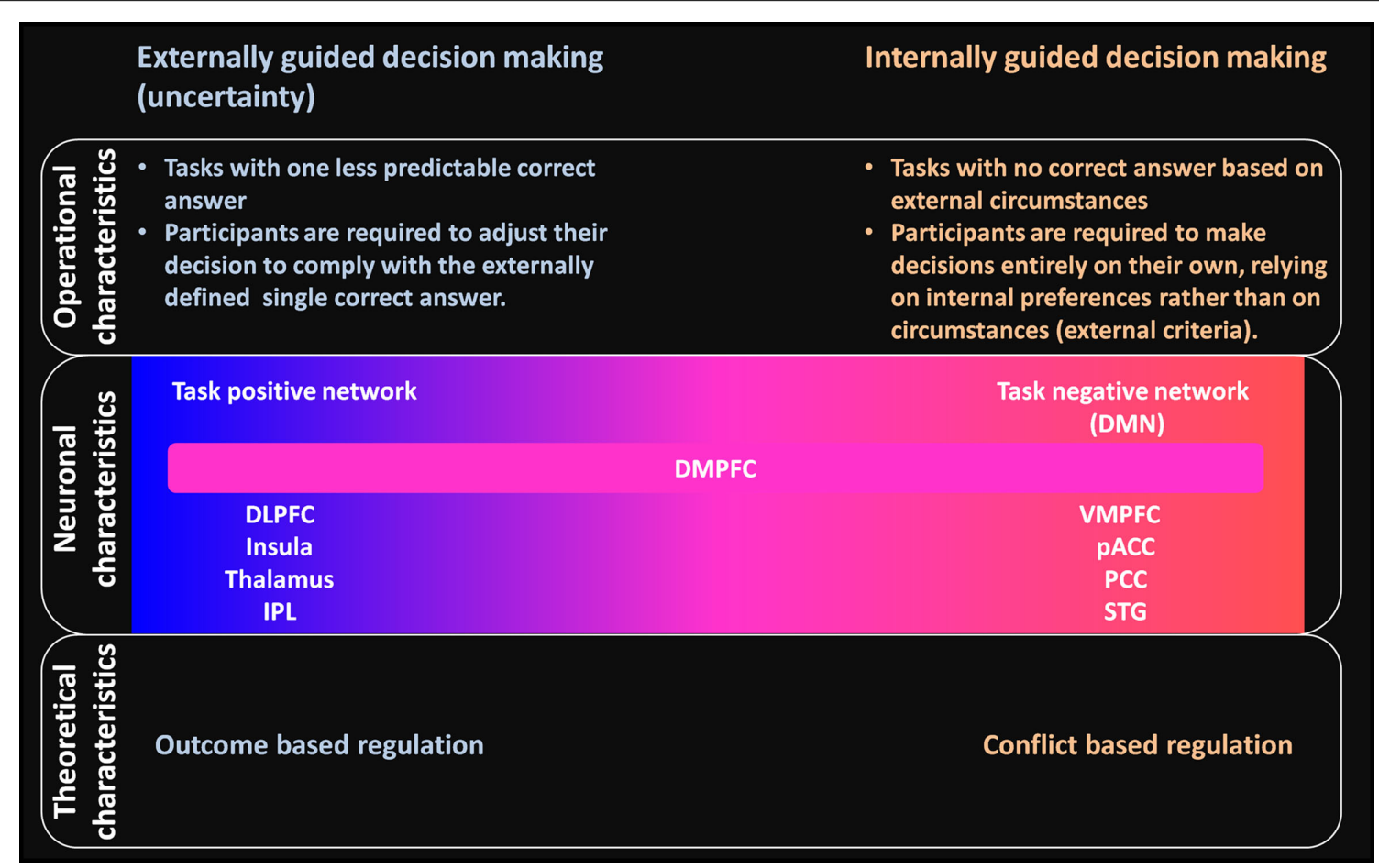

FIGURE 4 | Schematic summary of differences and relations between externally and internally guided decision-making in terms of operational, neuronal, and theoretical characteristics. Operational characteristics: clear differences are apparent between these two types of decision-making related to the availability of an externally determined correct answer. Neuronal characteristics: externally guided decision-making under uncertainty is mainly supported by the task-positive network (DLPFC-insula-thalamus-IPL

network). In contrast, internally guided decision-making is supported mainly by the task negative, default mode network (DMN). The DMPFC is commonly activated in decision making of these kinds and has functional relations with task-positive and task-negative networks. No clear boundary separates decision making processes of different kinds: each decision-making task can be located on the continuum. The extent to which the

DLPFC-insula-thalamus-IPL or the VMPFC-pACC-PCC-STG networks becomes involved would differ depending on the decision-making situation. Theoretical characteristics: conflict-based regulation is expected to have an important role for internally guided decision-making instead of

outcome-based regulation in the case of externally guided decision-making. The networks for internally guided decision-making are probably modulated according to the amount of conflict evaluated within dACC. decision-making (Figure 2B). The VMPFC was, however, limited to internally guided decision-making, even in that comparison. This evidence suggests that the activation of VMPFC-pACCPCC-STG network was caused neither by uncertainty related to an externally determined correct answer nor by social interaction.

Our results first revealed the neural substrates associated specifically with internally guided decision-making, as distinguished from the neural substrates associated specifically with externally guided decision-making under uncertainty. Externally guided decision-making under uncertainty is probably insufficient to account for our decision-making in everyday life.

\section{Balance between the selected studies for externally guided decision-making under uncertainty and internally guided decision-making}

Before further discussion related to meta-analysis results, the difference of stimulus type (verbal or non-verbal) used in externally guided decision-making under uncertainty and in internally guided decision-making should be explained. Verbal stimuli tended to be used more in internally guided decision-making; non-verbal stimuli were used more in externally guided decisionmaking under uncertainty (see Table A1 in Appendix).
Based on the following four reasons, however, we conclude that the regions observed in our meta-analysis results were not attributable to the difference of stimulus type. First, in every study included in the present meta-analysis, stimuli of the same type with experimental conditions were used in control conditions. For that reason, the coordinates from these studies were not specific to the stimulus type itself, but were specific to uncertainty or absence of an objective correct answer. Second, previous meta-analytical studies of neural substrates for working memory (Owen et al., 2005) and associative learning (Chein and Schneider, 2005) demonstrated broadly similar activation patterns for verbal and non-verbal stimuli including the regions observed in externally guided decision-making under uncertainty. Third, regarding internally guided decision-making, studies included in our metaanalysis and which used non-verbal stimuli (Paulus and Frank, 2003; Johnson et al., 2005; Jacobsen et al., 2006; Chen et al., 2010; Hare et al., 2010) yielded results indicating similar neural substrates with our meta-analysis results. Fourth, although Kobayashi et al. (2007) observed similar brain regions with internally guided decision-making by their mentalizing task, no increased activities within these regions were observed using verbal stimuli compared to non-verbal stimuli. 
We found no other significant difference between externally and internally guided decision-making with respect to the stimulus modality (visual or auditory), the sample size, the quality of the statistical analysis (corrected, uncorrected), and differences of reaction times between the experimental condition (uncertain, social, or internally guided) and control condition. Moreover, the reaction times in the experimental condition were not significantly longer than those in the control condition in either the externally guided decision-making under uncertainty or the internally guided decision-making. Based on these results, we conclude that the brain region observation results were not attributable to these factors.

\section{Internally guided decision-making and intrinsic brain activity}

In our meta-analysis results, the DMPFC-DLPFC-insulathalamus-IPL network was activated consistently in externally guided decision-making under uncertainty. In contrast, VMPFCpACC-PCC-STG network was activated in internally guided decision-making. This difference is similar to the distinction into two complementary networks, task-positive networks and tasknegative networks, called default-mode networks (DMN; Fox et al., 2005; Broyd et al., 2009; Hampson et al., 2010; Kim et al., 2010; Northoff et al., 2010; Wu et al., 2011a). The task-positive network is known to be activated consistently during goal-directed/externally oriented cognitive tasks, and it is known to include DLPFC, insula, IPL, thalamus, (pre-)SMA, dACC, and the cerebellum (Cabeza and Nyberg, 2000; Fox et al., 2005; Owen et al., 2005; Kim et al., 2010; for detailed hypothetical explanations of the functions of observed regions in externally guided decision-making, see Mohr et al., 2010a).

In contrast, the DMN consists mainly of cortical midline structures (Gusnard and Raichle, 2001; Raichle and Gusnard, 2005) and comprises MPFC, pACC, PCC, and superior temporal/inferior parietal cortex (Fox et al., 2005; Kim et al., 2010; Qin and Northoff, 2011). The DMN is more active at rest than during externally oriented cognitive tasks (Raichle et al., 2001; Buckner et al., 2008b). The regions within DMN are known to show a high degree of functional connectivity during rest (Raichle et al., 2001; Beckmann et al., 2005; Raichle and Snyder, 2007; Buckner et al., 2008a). Interestingly, the DMN and task-positive network are temporally anticorrelated such that task-induced activation within the taskpositive network is associated with attenuation of the DMN (Fox et al., 2005, 2009). These physiological phenomena are thought to reflect stimulus-independent thought (e.g., mind-wandering; Mason et al., 2007; Christoff et al., 2009), which has been studied since the 1960s from a naturalistic viewpoint (Singer and Antrobus, 1962, 1963; Antrobus et al., 1966, 1970; Wollman and Antrobus, 1986).

The DMN is also activated by a task that requires processing internally generated information, including self-reference (Kelley et al., 2002; Northoff et al., 2006), episodic memory retrieval (Buckner et al., 2008b), envisioning the future (Szpunar et al., 2007), mental imaginary (Hassabis et al., 2007; Daselaar et al., 2010), and mentalizing (Gusnard et al., 2001; Amodio and Frith, 2006). Because of the long lists of psychological contents related to the DMN, it is difficult to attribute any specific psychological function to task-negative regions. The DMN is often summarized more physiologically as the reflection of intrinsic brain activity in the context of neuroscience (for detailed reviews about task-positive and DMN, see Broyd et al., 2009; Northoff et al., 2010).

Intrinsic brain activity during a resting state is known to affect a stimulus-induced activity (Northoff et al., 2010). For instance, Northoff et al. (2007) measured the level of g-aminobutyric acid (GABA) in pACC, which is part of the DMN during a resting state using magnetic resonance spectroscopy (MRS), in addition to the blood oxygen level dependent (BOLD) response during an emotion judgment task using fMRI. The resting-state level of GABA in the pACC correlated with the degree of decreased BOLD response in the same region induced by an emotional judgment task. This study demonstrated that the resting-state concentration of GABA in the pACC can indeed impact upon stimulus-induced activity changes in the same region pACC.

Based on the rest-stimulus interaction and the overlap between the network for internally guided decision-making with DMN, internally guided decision-making seems to be based largely on intrinsic brain activity.

Taken together, by linking with the notions about the DMN, our meta-analysis results suggest that the decision in internally guided decision-making is based largely on intrinsic brain activity within the DMN (see Figure 4 for schematic summary). This implication from physiological evidence has high affinity with the psychological nature of internally guided decision-making: decision in internally guided decision-making depends on the participant's own criteria rather than on circumstantial criteria. Internally guided decision-making might be modulated directly by intrinsic brain activity, which can be assessed according to the resting-state brain activity.

\section{THEORETICAL DIFFERENCES BETWEEN EXTERNALLY AND INTERNALLY GUIDED DECISION-MAKING}

Outcome-based regulation and conflict-based regulation

Is internally guided decision-making modulated solely by intrinsic brain activity within the DMN? As described earlier in the review part of this report, it is known that the outcomes and feedback are used to regulate externally guided decision-making process (e.g., RL model) to avoid error decision. The outcome-based regulation process is not applicable to internally guided decision-making that does not presuppose the presence of outcomes and feedback (i.e., an objectively correct answer). Is there any regulatory process in internally guided decision-making, as there is in externally guided decision-making?

A possible regulatory process for internally guided decisionmaking is conflict-based regulation instead of outcome-based regulation in the case of externally guided decision-making (see Figure 4). Conflict is defined psychologically and computationally as the simultaneous activation of incompatible representations (Botvinick et al., 2001). The abilities of monitoring and regulation of conflict have been investigated extensively in cognitive psychology and neuroscience. Their emphases have been made predominantly on the conflict between error and correct response tendencies using tasks which strongly activate the error response (e.g., Flanker task, Ullsperger and von Cramon, 2001; Takezawa and Miyatani, 2005; Stroop task, Stroop, 1935; MacDonald et al., 2000a; and Simon task, Masaki et al., 2007). Several neuroimaging 
studies have documented that greater dACC activation is observed when participants are confronted with situations that demand detection of conflict (MacDonald et al., 2000b; Milham et al., 2003; Kerns et al., 2004; Egner and Hirsch, 2005), whereas the cognitive regulation of conflict (e.g., attentional modulation) is apparently related to the LPFC to reduce conflict (Botvinick et al., 2001, 2004; Kerns et al., 2004).

In addition to the conflict between error and correct response, the dACC evaluates conflict that occurs during internally guided decision-making (Greene et al., 2004; Forstmann et al., 2008; Knutson et al., 2008; Nakao et al., 2009a, 2010a,c; Sommer et al., 2010; Caspers et al., 2011; Kahane et al., 2011). In these studies, the conflict was manipulated based on the number of choices (Forstmann et al., 2008), scenarios of types (Kahane et al., 2011), ratings for each stimulus (Nakao et al., 2009a, 2010c), the chosen frequency of each stimulus (Nakao et al., 2010a), or reaction times (Greene et al., 2004; Knutson et al., 2008; Sommer et al., 2010; Caspers et al., 2011). Irrespective of the mode of conflict manipulation, higher dACC activities were observed in a large-conflict condition than in a small conflict condition during internally guided decision-making in these studies. This evidence suggests that dACC evaluates the conflict between possible decision branches in internally guided decision-making.

The regulation process used to reduce conflict in internally guided decision-making is probably different from that of externally guided decision-making (Lieberman and Eisenberger, 2005; Nakao et al., 2009b, 2010a,c; Chen et al., 2010). Instead of LPFC in the case of externally guided decision-making, MPFC and PCC as the part of the DMN associate with reduction of the conflict. Using psychophysiological interaction (PPI) analyses of fMRI data, Chen et al. (2010) showed that the dACC co-varied significantly more highly with the DMPFC and PCC during a face preference judgment task with no objective correct answer when compared to the control task: a gender judgment task with one correct answer. Similarly, Nakao et al. (2010c) reported that dACC has functional connectivity with VMPFC only during an occupational choice task, as internally guided decision-making, and not during a word-length judgment task. These results suggest that the MPFC and PCC as the parts of the DMN are modulated in response to the amount of conflict evaluated within dACC to reduce conflict during internally guided decision-making (Nakao et al., 2009b, 2010a,c).

One might argue that the dACC is not observed in our meta-analysis results for internally guided decision-making, which means that dACC does not function in internally guided decisionmaking. As described above, the evaluation of conflict within dACC works in situations with and without an objective correct answer. Additionally, the function of dACC is not limited to evaluation of conflict. It includes detection of error (Garavan et al., 2003; de Bruijn et al., 2009) and evaluation of the action value (Rushworth et al., 2007; Walton et al., 2007): dACC can be activated during externally guided decision-making for these functions. For these reasons, dACC activation was not shown in the meta-analysis results for internally guided decision-making based on the previous studies' contrasts of internal decision-making vs. a control task with one objective correct answer without uncertainty (see review part and Table A1 in "Appendix" for details of the contrasts). We did not include the contrast of large-conflict vs. small conflict in internally guided decision-making as well as results from PPI analyses in our meta-analysis because these did not fit our main aim. However, regarding results from previous studies about conflict evaluation during internally guided decision-making, conflict is evaluated within dACC during internally guided decisionmaking. The evaluated conflict affects the regulation process, which differs from externally guided decision-making.

Taken together, instead of outcome-based regulation in externally guided decision-making, conflict-based regulation might have an important role in internally guided decision-making. The internally guided decision-making is probably based not only on intrinsic brain activity within DMN but also on the dACC as the part of task-positive network.

\section{Modulation from attentional network in internally guided decision-making}

Internally guided decision-making, which is supported mainly by the DMN, might also be modulated in anticorrelated way by the network for attentional control. Corbetta et al. (2008) and Corbetta and Shulman (2002) proposed that networks of two types are involved in attending to environmental stimuli: a dorsal frontoparietal network and a ventral frontoparietal network. The dorsal frontoparietal network includes the dorsal parietal cortex (particularly the intraparietal sulcus and superior parietal lobule) and the dorsal frontal cortex (precentral sulcus and frontal eye field; see Figure 2 of Corbetta et al., 2008). The ventral frontoparietal network includes the temporoparietal junction and ventral frontal cortex (i.e., middle frontal gyrus, inferior frontal gyrus, frontal operculum, and anterior insula). When focusing attention on an object, the dorsal frontoparietal network is activated, but the ventral frontoparietal network is deactivated. When an unexpected but important event is evoked, both attentional networks are activated to reorient the attention.

Both of these networks consist mainly of lateral cortical regions (i.e., task-positive network), and do not include the cortical midline structure within the DMN, which is mainly observed in internally guided decision-making. However, the activity within the dorsal frontoparietal network is negatively correlated with the DMN activity (Fox et al., 2005; Golland et al., 2007; Corbetta et al., 2008). When the dorsal frontoparietal network is activated, the DMN is deactivated, and vice versa. Such functional connectivity was not observed between the ventral frontoparietal network and the DMN (Corbetta et al., 2008). Although no study has investigated the role of the top-down attentional control in internally guided decision-making, it is possible that the attentional network affect to internally guided decision-making in an anticorrelated way. For instance, when the dorsal frontoparietal network is activated and the ventral frontoparietal network is deactivated (i.e., when attention is focused on external stimuli), the processes for internally guided decision-making are expected to be attenuated.

\section{COMMONALITIES BETWEEN EXTERNALLY AND INTERNALLY GUIDED DECISION-MAKING}

Overlap between externally and internally guided decision-making

Our meta-analysis results showed that the DMPFC is activated in externally guided decision-making under uncertainty, that in a 
social situation, and internally guided decision-making. Psychologically, this result suggests that the DMPFC is not modulated solely by the uncertainty of outcome, social situation, or nonavailability of outcome, and that it has common functions in decision-making of these kinds. Physiologically, our results suggest that the DMPFC is co-activated both with DLPFC-insulathalamus-IPL and/or VMPFC-pACC-PCC-STG networks, and that it has functional relations with these networks.

One might want to argue that the overlap within DMPFC does not reflect that the area was activated both in externally and internally guided decision-making, but the DMPFC was observed because of the extended area from SMA (BA6) in externally guided decision-making and the extended area from VMPFC in internally guided decision-making. That is, the DMPFC observed in externally guided decision-making was caused by the activation within SMA and using a spherical kernel of $10 \mathrm{~mm}$ radius in MKDA, it was expanded to the DMPFC (BA8). In contrast, the DMPFC observed in internally guided decision-making was caused by the activity in VMPFC and by a spherical kernel, it was expanded to the area DMPFC. However, as Figure 2 shows, the area observed in internally guided decision-making was expanded to the posterior part of the overlap. Furthermore, the overlapped area includes the central part of DMPFC observed in externally guided decisionmaking (see Figures 1A and 2A). Based on these observations, it is implausible that the result of DMPFC was the overlap between the edges of the spherical kernels. It would be reasonable to infer that the overlapped area was activated consistently both in externally and internally guided decision-making.

Another possible confounding factor reflected in the overlap is the task difficulty. It is possible that the experimental tasks in both externally guided (i.e., uncertain condition) and internally guided circumstances were more difficult than the control tasks, and that the difference of difficulty was reflected in the DMPFC activation both in externally and internally guided decision-making. However, to assess the effect of the difference of task difficulty between experimental and control conditions, we examined the reaction time difference between these conditions. Results show no significant difference either in externally guided or in internally guided decision-making. The overlap within DMPFC is not expected to reflect the difference of task difficulty between experimental and control tasks.

Although the specific function of the DMPFC remains unclear, one possible role suggested by our result is that it integrates signals from task-positive regions and/or task-negative regions to bias either choice of behavior (see Figure 4), which was also proposed in previous articles (Volz et al., 2006; Nakao et al., 2009b). Depending on whether an objective correct answer is available or not, the DLPFC-insula-thalamus-IPL network or VMPFC-pACC-PCCSTG network is strongly activated. However, irrespective of which network is strongly activated, the DMPFC would receive the signals from the activated network(s), then integrate and mediate these signals to the motor control regions to output. In fact, the DMPFC has a strong connection with motor areas (Averbeck and Seo, 2008).

Ochsner et al. (2004) and Ochsner and Gross (2005) reported that the DMPFC was associated with different forms of cognitive control over emotional response. This fact suggests that the DMPFC is the node point between cognition and emotion. The DMPFC might be suited to integrate relevant cognitive and emotional processes in externally and internally guided decisionmaking. For that reason, it is involved in decision-making of both types.

One might be surprised that only the DMPFC was overlapped between these two types of decision-making tasks. One possible reason for the small fraction of overlap is that the data used in meta-analysis were already contrasted in previous studies. Both in the externally guided decision-making under uncertainty and internally guided decision-making, previous studies used a control task which required participants to make judgment in the situation with an objective correct answer without uncertainty. The brain regions which have functions in the control task were not reflected in the results for externally guided decision-making under uncertainty and internally guided decision-making. Therefore, our results might show the small fraction of overlapping. For example, the visual or auditory cortex for stimulus input, motor area for response, and dACC for regulation process can be activated during the control task. The striatum, amygdala, and orbitofrontal cortex for reward expectation can also be activated in the control task with reward feedback (e.g., pure monetary rewards task in Moll et al., 2006, and a gambling task using learned rules in Bhanji et al., 2010). We should note that we cannot conclude that the regions which were not observed in the meta-analysis have no function in these decision-making processes.

Another possible reason for the limited overlap area is the nature of MKDA. The MKDA (and other methods of metaanalyses) shows only the consistently activated regions in each category, although this is the aim of the meta-analysis. Consequently, for example, even when one of the studies of internally guided decision-making reported insula activity, such as that of Johnson et al. (2005), it was not reflected in the result from MKDA for internally guided decision-making. Therefore, although the insula was observed in the results of MKDA for externally guided decision-making, that region was not observed as a common region between externally and internally guided decision-making. Again, we should note carefully that the regions that were not observed using MKDA are not equal to the regions which have no function in decision-making. What we can know from the metaanalysis is that the observed regions were observed consistently in previous studies. This point is explained further in the following section.

\section{Relation between externally and internally guided decision-making}

In this report, to examine internally guided decision-making specifically as distinguished from externally guided decisionmaking, we categorized decision-making into externally and internally guided decision-making conceptually and methodologically. Consequently, we showed a difference of neural networks between these two. These two neural networks are, however, thought to be not completely independent of each other. They are merely the two extremes of a single continuum (see Figure 4). Each decision-making task can be located on the continuum, and the extent to which the DLPFC-insula-thalamus-IPL or the VMPFCpACC-PCC-STG networks become involved is expected to differ depending on the decision-making situation. 
In fact, several studies included in externally guided decisionmaking have shown activation within the network for internally guided decision-making (e.g., VMPFC, Elliott et al., 1999; Callan et al., 2009; PCC, Coricelli and Nagel, 2009; STG, Elliott et al., 1999; Elliott et al., 2006; Coricelli and Nagel, 2009; and vice versa DLPFC, Johnson et al., 2005; Greene and Paxton, 2009; Schleim et al., 2011; insula, Johnson et al., 2005; IPL, Chen et al., 2010). In addition, Pearson et al. (2011) reviewed mainly monkey singleneuron recording studies and implicated PCC as the part of DMN which has a role in externally guided decision-making. The clear distinctive neural substrates were observed in our meta-analysis because the results of meta-analysis show only the consistently activated regions in each category. This feature functioned well to reveal regions associated with the two extreme categories. However, non-activated regions from MKDA analysis are not equal to non-participating regions in each category of decision-making.

When participants refer to criteria that are probably used predominantly in internally guided decision-making, the VMPFCpACC-PCC-STG network was activated even in externally guided decision-making. For instance, Hampton et al. (2008) reported increased VMPFC and STG activities during externally guided decision-making in a social situation when they used a computational model incorporating referencing process of one's own actions to analyze fMRI data (see the review section for additional details). Furthermore, Goel and Dolan (2003) used a deductive reasoning task (e.g., "No harmful substances are natural; All poisons are natural; $\therefore$ No poisons are harmful"... true, false, or unsure) with one objective correct answer. They observed increased VMPFC activity when participants reached a decision based on their internal beliefs about the world (e.g., false response for "No poisons are harmful" based on the belief that "Poisons are harmful") instead of logical reasoning (e.g., true response for "No poisons are harmful"). Even in the case of externally guided decision-making, the network that functions predominantly for internally guided decision-making is activated to some degree depending on the task type and the participant's strategy.

Taken together, although one might wish to distinguish decision-making as two completely different phenomena - externally guided or internally guided - such a distinction between networks of the two types becomes relevant based on those earlier studies. How these two networks interact and how they are integrated during real-life decision-making remains to be resolved. However, our meta-analysis results at least suggest that two complementary networks are involved in decision-making and that the DMPFC serves some role in the integrative process.

\section{FUTURE DIRECTIONS}

Our meta-analysis revealed that the neural network used predominantly for internally guided decision-making differs from that for externally guided decision-making under uncertainty. This result suggests that studying only externally guided decision-making under uncertainty is insufficient to account for decision-making processes that take place in a human brain. It is necessary to examine internally guided decision-making more specifically to elucidate the psychological and neural mechanisms of human decisionmaking comprehensively. Furthermore, it would be beneficial to investigate how the two neural substrates for internally and externally guided decision-making mutually interact in day-to-day decision-making situations.

Based on the discussion presented above, we propose two possible directions to investigate internally guided decision-making: rest-stimulus interaction and conflict-based regulation.

\section{Rest-stimulus interaction}

The network for internally guided decision-making overlapped with the DMN. This fact implies that internally guided decisionmaking is strongly affected by resting-state brain activities. Investigating how the resting state affects the decision-making process (i.e., rest-stimulus interaction in decision-making) is a key directive leading to understanding of internally guided decisionmaking. The number of studies investigating the rest-stimulus interactions is growing (Greicius and Menon, 2004; Boly et al., 2007; Northoff et al., 2007, 2010; Wiebking et al., 2010, 2011; Duncan et al., 2011). Using the methods in those earlier studies, further detailed neuronal characteristics of internally guided decision-making would be revealed.

For example, the resting-state EEG for several minutes before conducting experimental tasks can be used to investigate the effect from intrinsic brain activity to internally guided decision-making. As decision-making tasks, color-similarity judgment and color preference judgment tasks which were used in Johnson et al. (2005) are expected to be useful for this purpose (similar tasks were also used by Goldberg and Podell, 1999, 2000). In both tasks, three colored squares are presented in each trial. The colored square presented in the upper center is the target color, and the squares presented in the lower left and right are choices. In the colorsimilarity judgment task, participants are asked to judge which choice is more similar to the target color ("Which is more similar?"). In the color preference judgment task, participants were asked to judge which color pair (target-choice pair) they prefer ("Which do you prefer?").

If intrinsic brain activity modulates internally guided decisionmaking, then the following is expected. Especially in participants who showed more increased resting-state activity (i.e., higher power spectral density during resting state), the color preference judgments are less biased from properties of external stimulus (e.g., color similarity; similar and dissimilar pairs are almost equally selected as the preferred pairs in those participants). In other words, participants who showed higher resting-state activity are expected to rely less on the properties of external stimulus for their preference judgment but might rely greatly on their internal criteria. In the color-similarity judgment, such a relation would not be observed even in cases where the judgment is difficult because of the similar color choices: the color-similarity judgment is the task of making a judgment based on the external stimulus properties. It is expected to be less affected by the intrinsic brain activity.

\section{Conflict-based regulation}

Regarding internally guided decision-making, outcomes and feedback are not available to adjust decision-making processes as externally guided decision-making. For that reason, outcomebased learning and regulation are not applicable to internally guided decision-making. Instead, previous results of studies have suggested that the amount of conflict is evaluated within dACC 
during internally guided decision-making (Greene et al., 2004; Forstmann et al., 2008; Knutson et al., 2008; Nakao et al., 2009a, 2010a,c; Sommer et al., 2010; Caspers et al., 2011; Kahane et al., 2011), and the signal from dACC is expected to regulate activation within DMN during internally guided decision-making (Chen et al., 2010; Nakao et al., 2010c). Details of conflict-based regulation processes in internally guided decision-making, however, might be less readily apparent. For instance, learning and regulation processes of what kinds are achieved to reduce conflict during internally guided decision-making remains unclear.

Several options are related to manipulation of conflict during internally guided decision-making: stimulus-based manipulation by the number of choices (Forstmann et al., 2008) or type of scenario (Kahane et al., 2011), and individualized manipulation based on reaction time (Greene et al., 2004; Knutson et al., 2008; Sommer et al., 2010; Caspers et al., 2011), ratings (Nakao et al., 2009a, 2010c; Jarcho et al., 2011), or chosen frequency of each stimulus (Nakao et al., 2010a). Although each manipulation has strong and weak points, all are applicable to internally and externally guided decision-making. These methods are useful to investigate the differences of conflict-based regulation process between decision-making of the two kinds.

To measure brain activities relating to conflict-based regulation process, not only fMRI but also event-related brain potentials (ERPs) are useful. The amplitudes of correct and conflict-related negativity (CRN; Simon-Thomas and Knight, 2005; Masaki et al., 2007; Nakao et al., 2010a) and N2 components (Yeung et al., 2004; Bartholow et al., 2005) are known to reflect the amount of conflict.
Nakao et al. (2010a) reported that the amount of conflict during internally guided decision-making (occupational choice in their case) is also reflected in the amplitude of the CRN.

\section{LIMITATIONS}

The meta-analysis results showed clearly that the activation of DMPFC and IFG occurred consistently in externally guided decision-making in social situations, and DMPFC was shared with internally guided decision-making. However, because of limitations imposed by insufficient studies of externally guided decisionmaking in a social situation, we were unable to compare that directly with internally guided decision-making. Replication of the current results when a more extensive and balanced selection of studies becomes available might therefore be warranted.

In the present study, externally guided decision-making under uncertainty has subcategories of two types (see review part and Table A1 in Appendix): we include the studies manipulating uncertainty by the probabilistic outcome and by the perceptual difficulty. One might argue that perceptual difficulty is different from the probabilistic outcome and that these two types should be separated. We included studies using perceptual difficulty for the following reasons. First, previous studies (Grinband et al., 2006; Callan et al., 2009; Banko et al., 2011) used the concept of uncertainty to describe the psychological state manipulated by perceptual difficulty. Second, our conceptual and operational definitions of uncertainty did not have a positive reason to exclude studies using perceptual difficulty. Third, as we described in the review part, the studies of the two subcategories of externally guided

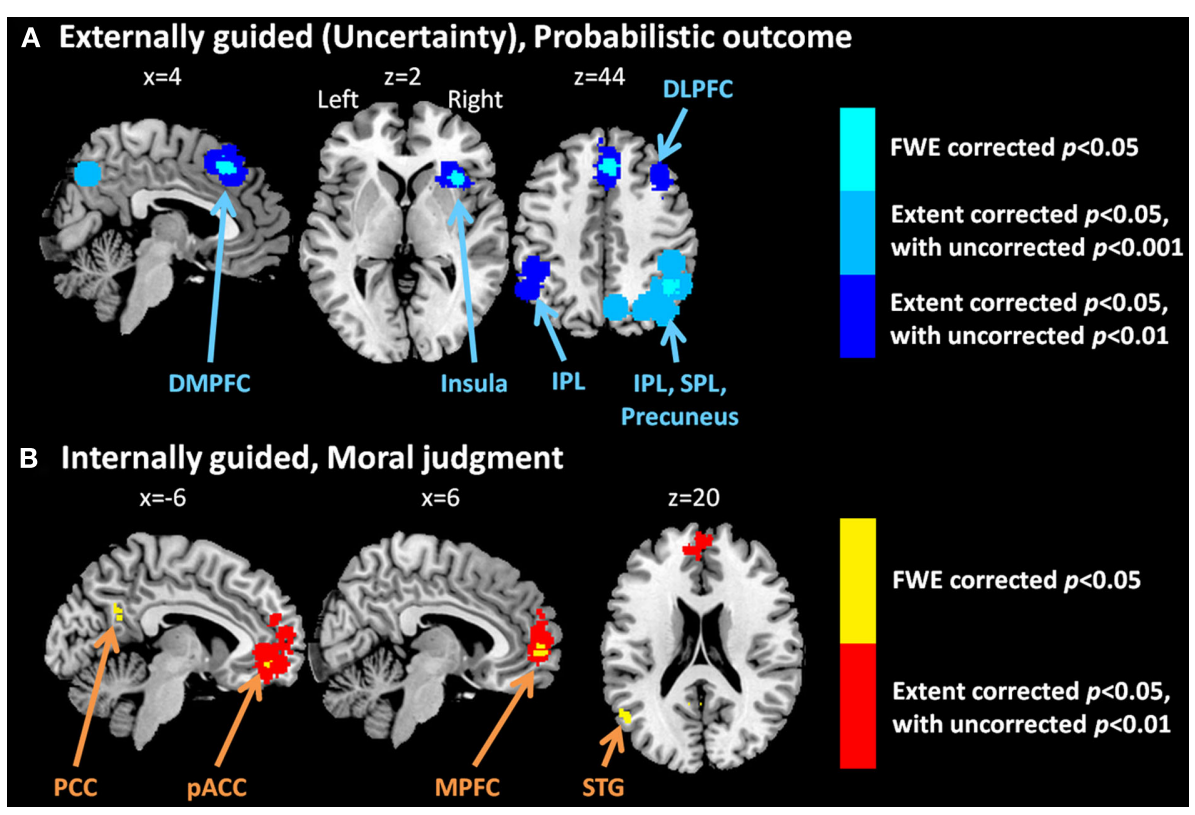

FIGURE 5 |The MKDA results for (A) externally guided decision-making under uncertainty using a probabilistic outcome, $(B)$ internally guided decision-making using moral judgment. Results from the different statistical thresholds are shown with different colors: cyan, pink, and yellow, a height threshold of familywise error rate (FWE) corrected at $p<0.05$; light blue, a stringent threshold of FWE corrected for the spatial extent at $p<0.05$ with primary thresholds of uncorrected $p<0.001$; blue, violet, and red, a medium threshold of FWE corrected for the spatial extent at $p<0.05$ with primary thresholds of uncorrected $p<0.01$. No clusters were identified at the stringent threshold in preference judgment. DMPFC, dorsomedial prefrontal cortex; DLPFC, dorsolateral prefrontal cortex; IPL, inferior parietal lobule; SPL, superior parietal lobule; IFG, inferior frontal gyrus; PACC, perigenual anterior cingulate cortex; PCC, posterior cingulate cortex; MPFC, medial prefrontal cortex; STG, superior temporal gyrus. 
decision-making under uncertainty reported similar neural substrates. Indeed, when we conduct meta-analysis using the studies of probabilistic outcome (see Figure 5A; Table 4), similar results to those obtained from the meta-analysis using the studies of both subcategories were observed (see Figure 1A; Table 2): we were unable to conduct a meta-analysis that includes studies of perceptual difficulty because of the scarcity of such studies (four studies). Furthermore, our results for externally guided decisionmaking under uncertainty closely resembled those of a previous meta-analysis study (Mohr et al., 2010a). Based on these reasons, we assume that including these two subcategories into externally guided decision-making was less problematic for our purpose of comparing externally and internally guided decision-making. However, these two types of externally guided decision-making can be supported by different neural substrates. This possibility should be addressed when sufficient numbers of studies for meta-analysis become available.

Similarly, we included two types of decision-making as internally guided decision-making (i.e., moral and preference decisions), based on our conceptual and operational definitions and similarity of neural substrates between these two types of studies. Although meta-analysis for preference judgment showed no significant regions because of the paucity of studies (seven studies), meta-analysis for moral judgment (see Figure 5B; Table 4) showed similar neural substrates to those found in the metaanalysis results for decision-making of these two types (see Figure 1C; Table 2). Based on these results, we assume here that using both moral and preference decision-making as internally guided decision-making is less problematic for our purposes.
However, it is possible that these subcategories present several differences of neural substrates because the preference judgment can be less influenced by social pressure than moral decisionmaking. In addition, different types of preference judgment (i.e., preference for color or for occupation) can be made based on different kinds of psychological criteria, and can be correlated with different neural substrates. It would be interesting to compare the neural substrates of these subcategories in future studies.

Because coordinate-based meta-analytical methods such as MKDA are based on spatial coordinates from neuroimaging data, they have been limited to PET and fMRI studies, and excluded EEG/ERP studies. Additionally, we did not include results from the analysis related to functional connectivity and computational model-based analysis into our meta-analysis. Although we tried to refer to studies of these kinds in review and discussion parts of this presentation, we note that our meta-analysis results reflect limited aspects of brain activities in externally and internally guided decision-making.

\section{CONCLUSION}

We compared different types of decision-making: externally and internally guided decision-making. Based on experimentaloperational and neural differences, we can distinguish these two basic types of decision-making from one another. Externally guided decision-making in situations with only one less-predictable correct answer was mainly supported by the DLPFC-insula-thalamus-IPL networks. Internally guided decision-making in which no correct answer based on

Table 4 | MKDA results for each sub-type of decision-making study

\begin{tabular}{|c|c|c|c|c|c|c|c|}
\hline \multirow[t]{2}{*}{ Types of decision-making } & \multirow[t]{2}{*}{ Region } & \multirow[t]{2}{*}{ BA } & \multicolumn{3}{|c|}{ MNI coordinates } & \multirow[t]{2}{*}{ Voxels } & \multirow[t]{2}{*}{ Maxstat } \\
\hline & & & $x$ & $y$ & $z$ & & \\
\hline & Dorsolateral prefrontal cortex (DLPFC) & $9,6,8$ & 40 & 22 & 40 & 960 & $0.26^{\dagger}$ \\
\hline & Insula & 47,13 & 36 & 20 & 2 & 73 & $0.4^{* *}$ \\
\hline & 40 & 46 & -54 & 44 & 100 & $0.35^{* *}$ & \\
\hline & IPL, Superior Parietal Lobule (SPL), Precuneus & $40,39,7,19$ & 12 & 38 & -54 & 3086 & $0.26^{*}$ \\
\hline \multirow[t]{2}{*}{ Internally guided, moral judgment } & $\begin{array}{l}\text { Medial prefrontal cortex } \\
\text { (MPFC) }\end{array}$ & 10 & 6 & 56 & 0 & 16 & $0.36 * *$ \\
\hline & & $10,11,9$ & -4 & 52 & 0 & 1647 & $0.32^{\dagger}$ \\
\hline
\end{tabular}

Because of low numbers of studies (four studies), we did not conduct meta-analysis for externally guided decision-making under uncertainty using perceptual difficulty. Internally guided decision-making using preference judgment showed no significant region because of the low number of studies (seven studies).

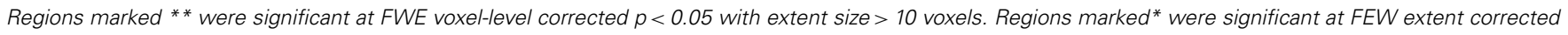

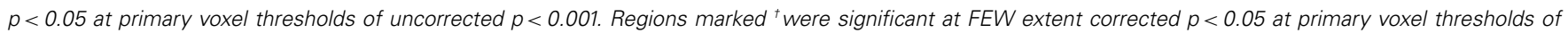
uncorrected $p<0.01$. Regions marked with ${ }^{*}$ and with ${ }^{\dagger}$ were reported if these were additional regions.

$B A$ denotes Brodman Area; Maxstat. denotes maximum of the $Z$ field. 
external circumstances is available, was supported by the VMPFC-pACC-PCC-STG network. Although the psychological and neural substrates of externally guided decision-making have been well identified, they remain unclear in the case of internally guided decision-making. This study of the substrates is of great interest to the field of decision-making itself in that it sheds some light on a form of decision-making that is prevalent in actual daily life. Beyond the field of decision-making, this line of investigation is also expected to contribute to improvement in our

\section{REFERENCES}

Abler, B., Herrnberger, B., Gron, G., and Spitzer, M. (2009). From uncertainty to reward: BOLD characteristics differentiate signaling pathways. BMC Neurosci. 10, 154. doi:10.1186/1471-2202-10-154

Amodio, D. M., and Frith, C. D. (2006). Meeting of minds: the medial frontal cortex and social cognition. Nat. Rev. Neurosci. 7, 268-277.

Antrobus, J. S., Singer, J. L., Goldstei, S., and Fortgang, M. (1970). Mindwandering and cognitive structure. Trans. N. Y. Acad. Sci. 32, 242-252.

Antrobus, J. S., Singer, J. L., and Greenber, S. (1966). Studies in stream of consciousness - experimental enhancement and suppression of spontaneous cognitive processes. Percept. Mot. Skills 23, 399-417.

Arana, F. S., Parkinson, J. A., Hinton, E., Holland, A. J., Owen, A. M., and Roberts, A. C. (2003). Dissociable contributions of the human amygdala and orbitofrontal cortex to incentive motivation and goal selection. J. Neurosci. 23, 9632-9638.

Assaf, M., Kahn, I., Pearlson, G. D., Johnson, M. R., Yeshurun, Y., Calhoun, V. D., and Hendler, T. (2009). Brain activity dissociates mentalization from motivation during an interpersonal competitive game. Brain Imaging Behav. 3, 24-37.

Averbeck, B. B., and Seo, M. (2008). The statistical neuroanatomy of frontal networks in the macaque. PLoS Comput. Biol. 4, e1000050. doi:10.1371/journal.pcbi.1000050

Balleine, B. W., and O'Doherty, J. P. (2010). Human and rodent homologies in action control: corticostriatal determinants of goal-directed and habitual action. Neuropsychopharmacology 35, 48-69.

Banko, E. M., Gal, V., Kortvelyes, J., Kovacs, G., and Vidnyanszky, Z. (2011). Dissociating the effect of noise on sensory processing and overall decision difficulty. J. Neurosci. 31, 2663-2674.

Bartholow, B. D., Pearson, M. A., Dickter, C. L., Sher, K. J., Fabiani, M., and Gratton, G. (2005). Strategic control and medial frontal negativity: beyond errors and response conflict. Psychophysiology 42, 33-42.

Bechara, A., Damasio, H., and Damasio, A. R. (2000). Emotion, decision making and the orbitofrontal cortex. Cereb. Cortex 10, 295-307.

Beckmann, C. F., Deluca, M., Devlin, J. T., and Smith, S. M. (2005). Investigations into resting-state connectivity using independent component analysis. Philos. Trans. R. Soc. Lond. B Biol. Sci. 360, 1001-1013.

Behrens, T. E., Woolrich, M. W., Walton, M. E., and Rushworth, M. F. (2007). Learning the value of information in an uncertain world. Nat. Neurosci. 10, 1214-1221.

Bhanji, J. P., Beer, J. S., and Bunge, S. A. (2010). Taking a gamble or playing by the rules: dissociable prefrontal systems implicated in probabilistic versus deterministic rule-based decisions. Neuroimage 49, 1810-1819.

Boly, M., Balteau, E., Schnakers, C., Degueldre, C., Moonen, G., Luxen, A., Phillips, C., Peigneux, P., Maquet, P., and Laureys, S. (2007). Baseline brain activity fluctuations predict somatosensory perception in humans. Proc. Natl. Acad. Sci. U.S.A. 104, 12187-12192.

Boorman, E. D., Behrens, T. E., Woolrich, M. W., and Rushworth, M. F. (2009). How green is the grass on the other side? Frontopolar cortex and the evidence in favor of alternative courses of action. Neuron 62, 733-743.

Botvinick, M. M., Braver, T. S., Barch, D. (2001). Conflict monitoring and cognitive control. Psychol. Rev. 108, 624-652.

Botvinick, M. M., Cohen, J. D., and Carter, C. S. (2004). Conflict monitoring and anterior cingulate cortex: an update. Trends Cogn. Sci. 8, 539-546.

Broyd, S. J., Demanuele, C., Debener, S., Helps, S. K., James, C. J., and SonugaBarke, E. J. (2009). Default-mode brain dysfunction in mental disorders: a systematic review. Neurosci. Biobehav. Rev. 33, 279-296.

Buckner, R. L., Andrews-Hanna, J. R., and Schacter, D. L. (2008a). D. M., Carter, C. S., and Cohen, J.

understanding of the function of the brain's resting state and its high activity, especially in the DMN that largely overlaps with observed regions in internally guided decision-making.

\section{ACKNOWLEDGMENTS}

This work was supported by a Grant-in-Aid for JSPS Fellows (20821) and for JSPS Postdoctoral Fellowships for Research Abroad (630) from the Japan Society for the Promotion of Science. CIHR, EJLB-CIHR, HDRF-ISAN, UMRF to Georg Northoff.

The brain's default network. Ann. N. Y. Acad. Sci. 1124, $1-38$.

Buckner, R. L., Andrews-Hanna, J. R., and Schacter, D. L. (2008b). The brain's default network: anatomy, function, and relevance to disease. Ann. N. Y. Acad. Sci. 1124, 1-38.

Cabeza, R., and Nyberg, L. (2000). Imaging cognition II: an empirical review of 275 PET and fMRI Studies. J. Cogn. Neurosci. 12, 1-47.

Callan, A. M., Osu, R., Yamagishi, Y., Callan, D. E., and Inoue, N. (2009). Neural correlates of resolving uncertainty in driver's decision making. Hum. Brain Mapp. 30, 2804-2812.

Caria, A., Weber, C., Brotz, D., Ramos, A., Ticini, L. F., Gharabaghi, A., Braun, C., and Birbaumer, N. (2011). Chronic stroke recovery after combined BCI training and physiotherapy: a case report. Psychophysiology $48,578-582$.

Casebeer, W. D. (2003). Moral cognition and its neural constituents. Nat. Rev. Neurosci. 4, 840-847.

Caspers, S., Heim, S., Lucas, M. G., Stephan, E., Fischer, L., Amunts, K., and Zilles, K. (2011). Moral concepts set decision strategies to abstract values. PLoS ONE 6, e18451. doi:10.1371/journal.pone.0018451

Chandrasekhar, P. V., Capra, C. M. Moore, S., Noussair, C., and Berns, G. S. (2008). Neurobiological regret and rejoice functions for aversive outcomes. Neuroimage 39, 1472-1484.

Chaudhry, A. M., Parkinson, J. A., Hinton, E. C., Owen, A. M., and Roberts, A. C. (2009). Preference judgements involve a network of structures within frontal, cingulate and insula cortices. Eur. J. Neurosci. 29, 1047-1055.

Chein, J. M., and Schneider, W. (2005). Neuroimaging studies of practicerelated change: fMRI and metaanalytic evidence of a domaingeneral control network for learning. Brain Res. Cogn. Brain Res. 25, 607-623.

Chen, A. C., Welsh, R. C., Liberzon, I., and Taylor, S. F. (2010). 'Do I like this person?' A network analysis of midline cortex during a social preference task. Neuroimage 51, 930-939.

Christoff, K., Gordon, A. M., Smallwood, J., Smith, R., and Schooler, J. W. (2009). Experience sampling during fMRI reveals default network and executive system contributions to mind wandering. Proc. Natl. Acad. Sci. U.S.A. 106, 8719-8724.

Cikara, M., Farnsworth, R. A., Harris, L. T., and Fiske, S. T. (2010). On the wrong side of the trolley track: neural correlates of relative social valuation. Soc. Cogn. Affect. Neurosci. 5, 404-413.

Cohen, M. X. (2007). Individual differences and the neural representations of reward expectation and reward prediction error. Soc. Cogn. Affect. Neurosci. 2, 20-30.

Corbetta, M., Patel, G., and Shulman, G. L. (2008). The reorienting system of the human brain: from environment to theory of mind. Neuron 58 , 306-324.

Corbetta, M., and Shulman, G. L. (2002). Control of goal-directed and stimulus-driven attention in the brain. Nat. Rev. Neurosci. 3, 201-215.

Coricelli, G., Dolan, R. J., and Sirigu, A. (2007). Brain, emotion and decision making: the paradigmatic example of regret. Trends Cogn. Sci. 11, 258-265.

Coricelli, G., and Nagel, R. (2009). Neural correlates of depth of strategic reasoning in medial prefrontal cortex. Proc. Natl. Acad. Sci. U.S.A. 106, 9163-9168.

Daselaar, S. M., Porat, Y., Huijbers, W., and Pennartz, C. M. (2010) Modality-specific and modalityindependent components of the human imagery system. Neuroimage 52, 677-685.

Daw, N. D., O’Doherty, J. P., Dayan, P., Seymour, B., and Dolan, R. J. (2006). Cortical substrates for exploratory decisions in humans. Nature 441, 876-879.

de Bruijn, E. R., De Lange, F. P., Von Cramon, D. Y., and Ullsperger, M. (2009). When errors are rewarding. J. Neurosci. 29, 12183-12186. 
Delgado, M. R., Frank, R. H., and Phelps, E. A. (2005a). Perceptions of moral character modulate the neural systems of reward during the trust game. Nat. Neurosci. 8, 1611-1618.

Delgado, M. R., Miller, M. M., Inati, S., and Phelps, E. A. (2005b). An fMRI study of reward-related probability learning. Neuroimage 24, 862-873.

Duncan, N. W., Enzi, B., Wiebking, C., and Northoff, G. (2011). Involvement of glutamate in rest-stimulus interaction between perigenual and supragenual anterior cingulate cortex: a combined fMRI-MRS study. Hum. Brain Mapp. 32, 2172-2182.

Egner, T., and Hirsch, J. (2005). The neural correlates and functional integration of cognitive control in a Stroop task. Neuroimage 24, 539-547.

Elliott, R., Rees, G., and Dolan, R. J. (1999). Ventromedial prefrontal cortex mediates guessing. Neuropsychologia 37, 403-411.

Elliott, R., Völlm, B., Drury, A., Mckie, S., Richardson, P., and Deakin, J. F. (2006). Co-operation with another player in a financially rewarded guessing game activates regions implicated in theory of mind. Soc. Neurosci. 1, 385-395.

Etkin, A., and Wager, T. D. (2007). Functional neuroimaging of anxiety: a meta-analysis of emotional processing in PTSD, social anxiety disorder, and specific phobia. Am. J. Psychiatry 164, 1476-1488.

Fan, Y., Duncan, N. W., De Greck, M., and Northoff, G. (2011). Is there a core neural network in empathy? An fMRI based quantitative metaanalysis. Neurosci. Biobehav. Rev. 35, 903-911.

Fellows, L. K. (2004). The cognitive neuroscience of human decision making: a review and conceptual framework. Behav. Cogn. Neurosci. Rev. 3, 159-172.

Forstmann, B., Brass, M., Koch, I., and Von Cramon, Y. (2006). Voluntary selection of task sets revealed by functional magnetic resonance imaging. J. Cogn. Neurosci. 18, 388-398.

Forstmann, B. U., Wolfensteller, U., Derrfuss, J., Neumann, J., Brass, M., Ridderinkhof, K. R., and Von Cramon, D. Y. (2008). When the choice is ours: context and agency modulate the neural bases of decisionmaking. PLoS ONE 3, el899. doi:10.1371/journal.pone.0001899

Fox, M. D., Snyder, A. Z., Vincent, J. L., Corbetta, M., Van Essen, D. C., and Raichle, M. E. (2005). The human brain is intrinsically organized into dynamic, anticorrelated functional networks. Proc. Natl. Acad. Sci. U.S.A. 102, 9673-9678.

Fox, M. D., Zhang, D., Snyder, A. Z., and Raichle, M. E. (2009). The global signal and observed anticorrelated resting state brain networks. J. Neurophysiol. 101, 3270-3283.

Frith, C. D., and Frith, U. (1999). Interacting minds: a biological basis. Science 286, 1692-1695.

Frith, C. D., and Singer, T. (2008). The role of social cognition in decision making. Philos. Trans. R. Soc. Lond. B Biol. Sci. 363, 3875-3886.

Gallagher, H. L., Jack, A. I., Roepstorff, A., and Frith, C.D. (2002). Imaging the intentional stance in a competitive game. Neuroimage 16, 814-821.

Garavan, H., Ross, T. J., Kaufman, J., and Stein, E. A. (2003). A midline dissociation between error-processing and response-conflict monitoring. Neuroimage 20, 1132-1139.

Glascher, J., Hampton, A. N., and O'Doherty, J. P. (2009). Determining a role for ventromedial prefrontal cortex in encoding actionbased value signals during rewardrelated decision making. Cereb. Cortex 19, 483-495.

Glimcher, P. W., and Rustichini, A. (2004). Neuroeconomics: the consilience of brain and decision. Science 306, 447-452.

Goel, V., and Dolan, R. J. (2003). Explaining modulation of reasoning by belief. Cognition 87, B11-B22.

Goldberg, E., and Podell, K. (1999). Adaptive versus veridical decision making and the frontal lobes. Conscious. Cogn. 8, 364-377.

Goldberg, E., and Podell, K. (2000). Adaptive decision making, ecological validity, and the frontal lobes. $J$. Clin. Exp. Neuropsychol. 22, 56-68.

Golland, Y., Bentin, S., Gelbard, H., Benjamini, Y., Heller, R., Nir, Y., Hasson, U., and Malach, R. (2007). Extrinsic and intrinsic systems in the posterior cortex of the human brain revealed during natural sensory stimulation. Cereb. Cortex 17, 766-777.

Greene, J. (2003). From neural 'is' to moral 'ought': what are the moral implications of neuroscientific moral psychology? Nat. Rev. Neurosci. 4, 846-850.

Greene, J., and Haidt, J. (2002). How (and where) does moral judgment work? Trends Cogn. Sci. 6, 517-523.

Greene, J. D., Nystrom, L. E., Engell, A. D., Darley, J. M., and Cohen, J. D. (2004). The neural bases of cognitive conflict and control in moral judgment. Neuron 44, 389-400.

Greene, J. D., and Paxton, J. M. (2009). Patterns of neural activity associated with honest and dishonest moral decisions. Proc. Natl. Acad. Sci. U.S.A. 106, 12506-12511.

Greicius, M. D., and Menon, V. (2004). Default-mode activity during a passive sensory task: uncoupled from deactivation but impacting activation. J. Cogn. Neurosci. 16, 1484-1492.

Grinband, J., Hirsch, J., and Ferrera, V. P. (2006). A neural representation of categorization uncertainty in the human brain. Neuron 49, 757-763.

Gusnard, D. A., Akbudak, E., Shulman, G. L., and Raichle, M. E. (2001). Medial prefrontal cortex and selfreferential mental activity: relation to a default mode of brain function. Proc. Natl. Acad. Sci. U.S.A. 98 4259-4264.

Gusnard, D. A., and Raichle, M. E. (2001). Searching for a baseline: functional imaging and the resting human brain. Nat. Rev. Neurosci. 2 , 685-694.

Hampson, M., Driesen, N., Roth, J. K., Gore, J. C., and Constable, R. T. (2010). Functional connectivity between task-positive and tasknegative brain areas and its relation to working memory performance. Magn. Reson. Imaging 28, 1051-1057.

Hampton, A. N., Bossaerts, P., and O'Doherty, J. P. (2006). The role of the ventromedial prefrontal cortex in abstract state-based inference during decision making in humans. J. Neurosci. 26, 8360-8367.

Hampton, A. N., Bossaerts, P., and O'Doherty, J. P. (2008). Neural correlates of mentalizing-related computations during strategic interactions in humans. Proc. Natl. Acad. Sci. U.S.A. 105, 6741-6746.

Hare, T. A., Camerer, C. F., Knoepfle, D. T., and Rangel, A. (2010). Value computations in ventral medial prefrontal cortex during charitable decision making incorporate input from regions involved in social cognition. J. Neurosci. 30, 583-590.

Hare, T. A., Camerer, C. F., and Rangel, A. (2009). Self-control in decisionmaking involves modulation of the vmPFC valuation system. Science 324, 646-648.

Hassabis, D., Kumaran, D., and Maguire, E. A. (2007). Using imagination to understand the neural basis of episodic memory. J. Neurosci. 27, 14365-14374.

Heekeren, H. R., Marrett, S., Bandettini, P. A., and Ungerleider, L. G. (2004). A general mechanism for perceptual decision-making in the human brain. Nature 431, 859-862.
Heekeren, H. R., Marrett, S., and Ungerleider, L. G. (2008). The neural systems that mediate human perceptual decision making. Nat. Rev. Neurosci. 9, 467-479.

Heekeren, H. R., Wartenburger, I., Schmidt, H., Prehn, K., Schwintowski, H. P., and Villringer, A. (2005). Influence of bodily harm on neural correlates of semantic and moral decision-making. Neuroimage 24, 887-897.

Heekeren, H. R., Wartenburger, I., Schmidt, H., Schwintowski, H.-P., and Villringer, A. (2003). An fMRI study of simple ethical decisionmaking. Neuroreport 14, 1215-1219.

Hsu, M., Bhatt, M., Adolphs, R., Tranel, D., and Camerer, C. F. (2005). Neural systems responding to degrees of uncertainty in human decisionmaking. Science 310, 1680-1683.

Huettel, S. (2006). Behavioral, but not reward, risk modulates activation of prefrontal, parietal, and insular cortices. Cogn. Affect. Behav. Neurosci. 6, 141-151.

Jacobsen, T., Schubotz, R. I., Hofel, L., and Cramon, D. Y. (2006). Brain correlates of aesthetic judgment of beauty. Neuroimage 29, 276-285.

Jarcho, J. M., Berkman, E. T., and Lieberman, M. D. (2011). The neural basis of rationalization: cognitive dissonance reduction during decisionmaking. Soc. Cogn. Affect. Neurosci. 6, 460-467.

Johnson, S. C., Schmitz, T. W. Kawahara-Baccus, T. N., Rowley, H. A., Alexander, A. L., Lee, J., and Davidson, R. J. (2005). The cerebral response during subjective choice with and without self-reference. $J$. Cogn. Neurosci. 17, 1897-1906.

Kahane, G., Wiech, K., Shackel, N., Farias, M., Savulescu, J., and Tracey, I. (2011). The neural basis of intuitive and counterintuitive moral judgment. Soc. Cogn. Affect. Neurosci.

Kelley, W. M., Macrae, C. N., Wyland, C. L., Caglar, S., Inati, S., and Heatherton, T. F. (2002). Finding the self? An event-related fMRI study. J. Cogn. Neurosci. 14, 785-794.

Kerns, J. G., Cohen, J. D., MaCdonald, A. W., Cho, R. Y., Stenger, V., and Carter, C. S. (2004). Anterior cingulate conflict monitoring and adjustments in control. Science 303, 1023-1026.

Kim, H., Adolphs, R., O’Doherty, J. P., and Shimojo, S. (2007). Temporal isolation of neural processes underlying face preference decisions. Proc. Natl. Acad. Sci. U.S.A. 104, 18253-18258.

Kim, H., Daselaar, S. M., and Cabeza, R. (2010). Overlapping brain activity 
between episodic memory encoding and retrieval: roles of the taskpositive and task-negative networks. Neuroimage 49, 1045-1054.

Kim, H., Shimojo, S., and O'Doherty, J. P. (2006). Is avoiding an aversive outcome rewarding? Neural substrates of avoidance learning in the human brain. PLoS Biol. 4, e233. doi:10.1371/journal.pbio.0040233

Knabb, J. J., Welsh, R. K., Ziebell, J. G., and Reimer, K. S. (2009). Neuroscience, moral reasoning, and the law. Behav. Sci. Law 27, 219-236.

Knutson, B., Rick, S., Wimmer, G. E., Prelec, D., and Loewenstein, G. (2007). Neural predictors of purchases. Neuron 53, 147-156.

Knutson, B., Taylor, J., Kaufman, M., Peterson, R., and Glover, G. (2005). Distributed neural representation of expected value. J. Neurosci. 25, 4806-4812.

Knutson, B., Wimmer, G. E., Rick, S., Hollon, N. G., Prelec, D., and Loewenstein, G. (2008). Neural antecedents of the endowment effect. Neuron 58, 814-822.

Kobayashi, C., Glover, G. H., and Temple, E. (2007). Children's and adults' neural bases of verbal and nonverbal 'theory of mind'. Neuropsychologia 45, 1522-1532.

Kober, H., Barrett, L. F., Joseph, J., BlissMoreau, E., Lindquist, K., and Wager, T. D. (2008). Functional grouping and cortical-subcortical interactions in emotion: a meta-analysis of neuroimaging studies. Neuroimage 42, 998-1031.

Krain, A. L., Wilson, A. M., Arbuckle, R., Castellanos, F. X., and Milham, M. P. (2006). Distinct neural mechanisms of risk and ambiguity: a metaanalysis of decision-making. Neuroimage 32 , 477-484.

Lee, D. (2008). Game theory and neural basis of social decision making. Nat. Neurosci. 11, 404-409.

Lieberman, M. D., and Eisenberger, N. I. (2005). "Conflict and habit: a social cognitive neuroscience approach to the self," in On Building, Defending and Regulating the Self: A Psychological Perspective, eds. A. Tesser, J. V. Wood, and D. A. Stapel. (New York, NY: Psychology Press), 77-102.

Linder, N. S., Uhl, G., Fliessbach, K., Trautner, P., Elger, C. E., and Weber, B. (2010). Organic labeling influences food valuation and choice. Neuroimage 53, 215-220.

Liu, X., Hairston, J., Schrier, M., and Fan, J. (2011). Common and distinct networks underlying reward valence and processing stages: a metaanalysis of functional neuroimaging studies. Neurosci. Biobehav. Rev. 35, 1219-1236.

MaCdonald, A. W., Cohen, J. D., Stenger, V. A., and Carter, C. S. (2000a). Dissociating the role of the dorsolateral prefrontal and anterior cingulate cortex in cognitive control. Science 288, 1835-1838.

MaCdonald, A. W. R., Cohen, J. D., Stenger, V. A., and Carter, C. S. (2000b). Dissociating the role of the dorsolateral prefrontal and anterior cingulate cortex in cognitive control. Science 288, 1835-1838.

Masaki, H., Falkenstein, M., Sturmer, B., Pinkpank, T., and Sommer, W. (2007). Does the error negativity reflect response conflict strength? Evidence from a Simon task. Psychophysiology 44, 579-585.

Mason, M. F., Norton, M. I., Van Horn, J. D., Wegner, D. M., Grafton, S. T., and Macrae, C. N. (2007). Wandering minds: the default network and stimulus-independent thought. Science 315, 393-395.

McCabe, D. P., and Castel, A. D. (2008). Seeing is believing: the effect of brain images on judgments of scientific reasoning. Cognition 107, 343-352.

Milham, M. P., Banich, M. T., and Barad, V. (2003). Competition for priority in processing increases prefrontal cortex's involvement in top-down control: an event-related fMRI study of the Stroop task. Cogn. Brain Res. 17, 212-222.

Mohr, P.N., Biele, G., and Heekeren, H.R. (2010a). Neural processing of risk. J. Neurosci. 30, 6613-6619.

Mohr, P.N., Li, S.C., and Heekeren, H.R. (2010b). Neuroeconomics and aging: neuromodulation of economic decision making in old age. Neurosci. Biobehav. Rev. 34, 678-688.

Moll, J., De Oliveira-Souza, R., Bramati, I. E., and Grafman, J. (2002). Functional networks in emotional moral and nonmoral social judgments. Neuroimage 16, 696-703.

Moll, J., Eslinger, P. J., and OliveiraSouza, R. (2001). Frontopolar and anterior temporal cortex activation in a moral judgment task: preliminary functional MRI results in normal subjects. Arq. Neuropsiquiatr. 59, 657-664.

Moll, J., Krueger, F., Zahn, R., Pardini, M., De Oliveira-Souza, R., and Grafman, J. (2006). Human fronto-mesolimbic networks guide decisions about charitable donation. Proc. Natl. Acad. Sci. U.S.A. 103, 15623-15628.

Moll, J., Zahn, R., De Oliveira-Souza, R., Krueger, F., and Grafman, J. (2005). The neural basis of human moral cognition. Nat. Rev. Neurosci. 6, 799-809.

Nakao, T., Mitsumoto, M., Nashiwa, H., Takamura, M., Tokunaga, S., Miyatani, M., Ohira, H., Katayama, K., Okamoto, A., and Watanabe, Y. (2010a). Self-knowledge reduces conflict by biasing one of plural possible answers. Pers. Soc. Psychol. Bull. 36, 455-469.

Nakao, T., Ohira, H., and Northoff, G. (2010b). Decision making and the medial prefrontal cortex function in social context. Jpn. J. Physiol. Psychol. Psychophysiol. , 45-55.

Nakao, T., Osumi, T., Ohira, H., Kasuya, Y., Shinoda, J., and Yamada, J. (2009a). Neural bases of behavior selection without an objective correct answer. Neurosci. Lett. 459, 30-34.

Nakao, T., Osumi, T., Ohira, H., Kasuya, Y., Shinoda, J., Yamada, J., and Northoff, G. (2010c). Medial prefrontal cortex - dorsal anterior cingulate cortex connectivity during behavior selection without an objective correct answer. Neurosci. Lett. 482, 220-224.

Nakao, T., Takezawa, T., Miyatani, M. and Ohira, H. (2009b). Medial prefrontal cortex and cognitive regulation. Psychologia 52, 93-109.

Northoff, G., Heinzel, A., De Greck, M., Bermpohl, F., Dobrowolny, H., and Panksepp, J. (2006). Selfreferential processing in our brain a meta-analysis of imaging studies on the self. Neuroimage 31, 440-457.

Northoff, G., Qin, P., and Nakao, T. (2010). Rest-stimulus interaction in the brain: a review. Trends Neurosci. 33, 277-284.

Northoff, G., Walter, M., Schulte, R. F., Beck, J., Dydak, U., Henning, A., Boeker, H., Grimm, S., and Boesiger, P. (2007). GABA concentrations in the human anterior cingulate cortex predict negative BOLD responses in fMRI. Nat. Neurosci. 10, 1515-1517.

O'Doherty, J., Dayan, P., Schultz, J., Deichmann, R., Friston, K., and Dolan, R. J. (2004). Dissociable roles of ventral and dorsal striatum in instrumental conditioning. Science 304, 452-454.

O'Doherty, J. P. (2004). Reward representations and reward-related learning in the human brain: insights from neuroimaging. Curr. Opin. Neurobiol. 14, 769-776.

O'Doherty, J. P. (2007). Lights, camembert, action! The role of human orbitofrontal cortex in encoding stimuli, rewards, and choices. Ann. N. Y. Acad. Sci. 1121, 254-272.
Ochsner, K. N., and Gross, J. J. (2005). The cognitive control of emotion. Trends Cogn. Sci. 9, 242-249.

Ochsner, K. N., Ray, R. D., Cooper, J. C., Robertson, E. R., Chopra S., Gabrieli, J. D., and Gross, J. J. (2004). For better or for worse: neural systems supporting the cognitive down- and up-regulation of negative emotion. Neuroimage 23, 483-499.

Ohira, H., Ichikawa, N., Nomura, M., Isowa, T., Kimura, K., Kanayama, N., Fukuyama, S., Shinoda, J., and Yamada, J. (2010). Brain and autonomic association accompanying stochastic decision-making. Neuroimage 49, 1024-1037.

Owen, A. M., Mcmillan, K. M., Laird, A. R., and Bullmore, E. (2005). Nback working memory paradigm: a meta-analysis of normative functional neuroimaging studies. Hum. Brain Mapp. 25, 46-59.

Paulus, M. P., and Frank, L. R. (2003). Ventromedial prefrontal cortex activation is critical for preference judgments. Neuroreport 14, 1311-1315.

Paulus, M. P., and Frank, L. R. (2006). Anterior cingulate activity modulates nonlinear decision weight function of uncertain prospects. $\mathrm{Neu}$ roimage 30, 668-677.

Pearson, J. M., Heilbronner, S. R., Barack, D. L., Hayden, B. Y., and Platt, M. L. (2011). Posterior cingulate cortex: adapting behavior to a changing world. Trends Cogn. Sci. 15, 143-151.

Piech, R. M., Lewis, J., Parkinson, C. H., Owen, A. M., Roberts, A. C., Downing, P. E., and Parkinson, J. A. (2009). Neural correlates of affective influence on choice. Brain Cogn. 72, 282-288.

Platt, M. L., and Huettel, S. A. (2008). Risky business: the neuroeconomics of decision making under uncertainty. Nat. Neurosci. 11, 398-403.

Prehn, K., Wartenburger, I., Meriau, K., Scheibe, C., Goodenough, O. R., Villringer, A., Van Der Meer, E., and Heekeren, H. R. (2008). Individual differences in moral judgment competence influence neural correlates of socio-normative judgments. Soc. Cogn. Affect. Neurosci. 3, 33-46.

Preuschoff, K., Quartz, S. R., and Bossaerts, P. (2008). Human insula activation reflects risk prediction errors as well as risk. J. Neurosci. 28, 2745-2752.

Qin, P., and Northoff, G. (2011). How is our self related to midline regions and the default-mode network? Neuroimage 57, 1221-1233.

Raichle, M. E., and Gusnard, D. A. (2005). Intrinsic brain activity sets 
the stage for expression of motivated behavior. J. Comp. Neurol. 493, 167-176.

Raichle, M. E., Macleod, A. M., Snyder, A. Z., Powers, W. J., Gusnard, D. A., and Shulman, G. L. (2001). A default mode of brain function. Proc. Natl. Acad. Sci. U.S.A. 98, 676-682.

Raichle, M. E., and Snyder, A. Z. (2007). A default mode of brain function: a brief history of an evolving idea. Neuroimage 37, 1083-1090; discussion 1097-1089.

Rangel, A., Camerer, C., and Montague, P. R. (2008). A framework for studying the neurobiology of value-based decision making. Nat. Rev. Neurosci. 9, 545-556.

Rangel, A., and Hare, T. (2010). Neural computations associated with goaldirected choice. Curr. Opin. Neurobiol. 20, 262-270.

Rilling, J., Gutman, D., Zeh, T., Pagnoni, G., Berns, G., and Kilts, C. (2002). A neural basis for social cooperation. Neuron 35, 395-405.

Rilling, J. K., Goldsmith, D. R., Glenn, A. L., Jairam, M. R., Elfenbein, H. A., Dagenais, J. E., Murdock, C. D., and Pagnoni, G. (2008a). The neural correlates of the affective response to unreciprocated cooperation. $\mathrm{Neu}$ ropsychologia 46, 1256-1266.

Rilling, J. K., King-Casas, B., and Sanfey, A. G. (2008b). The neurobiology of social decision-making. Curr. Opin. Neurobiol. 18, 159-165.

Rilling, J. K., Sanfey, A. G., Aronson, J. A., Nystrom, L. E., and Cohen, J. D. (2004). The neural correlates of theory of mind within interpersonal interactions. Neuroimage 22, 1694-1703.

Roberts, A. C. (2006). Primate orbitofrontal cortex and adaptive behaviour. Trends Cogn. Sci. 10, 83-90.

Rolls, E. T. (2000). The orbitofrontal cortex and reward. Cereb. Cortex 10, 284-294.

Rolls, E. T. (2004). The functions of the orbitofrontal cortex. Brain Cogn. 55, 11-29.

Rolls, E. T., and Grabenhorst, F. (2008). The orbitofrontal cortex and beyond: from affect to decision-making. Prog. Neurobiol. 86, 216-244.

Rolls, E. T., McCabe, C., and Redoute, J. (2008). Expected value, reward outcome, and temporal difference error representations in a probabilistic decision task. Cereb. Cortex 18 652-663.

Rorden, C. (2007). MRICroN [Online]. Available at: www.sph. sc.edu/comd/rorden/mricron/index. html (Accessed May 4th, 2010).
Rubia, K., Russell, T., Overmeyer, S., Brammer, M. J., Bullmore, E. T., Sharma, T., Simmons, A., Williams, S. C., Giampietro, V., Andrew, C. M., and Taylor, E. (2001). Mapping motor inhibition: conjunctive brain activations across different versions of go/no-go and stop tasks. $\mathrm{Neu}$ roimage 13, 250-261.

Rushworth, M. F., and Behrens, T. E. (2008). Choice, uncertainty and value in prefrontal and cingulate cortex. Nat. Neurosci. 11, 389-397.

Rushworth, M. F., Behrens, T. E., Rudebeck, P. H., and Walton, M. E. (2007). Contrasting roles for cingulate and orbitofrontal cortex in decisions and social behaviour. Trends Cogn. Sci. 11, 168-176.

Sanfey, A. G. (2007). Social decisionmaking: insights from game theory and neuroscience. Science 318, 598-602.

Sanfey, A. G., and Chang, L. J. (2008). Multiple systems in decision making. Ann. N.Y. Acad. Sci. 1128, 53-62.

Sanfey, A. G., and Cohen, J. D. (2004). Is knowing always feeling? Proc. Natl. Acad. Sci. U.S.A. 101, 16709-16710.

Sanfey, A. G., Loewenstein, G., Mcclure, S. M., and Cohen, J.D. (2006) Neuroeconomics: cross-currents in research on decision-making. Trends Cogn. Sci. 10, 108-116.

Sanfey, A. G., Rilling, J. K., Aronson, J. A., Nystrom, L. E., and Cohen, J. D. (2003). The neural basis of economic decision-making in the Ultimatum Game. Science 300, 1755-1758.

Santos, J. P., Seixas, D., Brandao, S., and Moutinho, L. (2011). Investigating the role of the ventromedial prefrontal cortex in the assessment of brands. Front. Neurosci. 5:77. doi:10.3389/fnins.2011.00077

Schaich Borg, J., Hynes, C., Van Horn, J., Grafton, S., and Sinnott-Armstrong, W. (2006). Consequences, action, and intention as factors in moral judgments: an fMRI investigation. $J$. Cogn. Neurosci. 18, 803-817.

Schleim, S., Spranger, T. M., Erk, S., and Walter, H. (2011). From moral to legal judgment: the influence of normative context in lawyers and other academics. Soc. Cogn. Affect. Neurosci. 6, 48-57.

Simon-Thomas, E. R., and Knight, R. T. (2005). Affective and cognitive modulation of performance monitoring: behavioral and ERP evidence. Cogn. Affect. Behav. Neurosci. 5, 362-372.

Singer, J. L., and Antrobus, J. S. (1962). A factor-analytic study of daydreaming and conceptually related cognitive and personality-variables. Am. Psychol. 17, 305-305.
Singer, J. L., and Antrobus, J. S. (1963). A factor-analytic study of daydreaming and conceptually-related cognitive and personality variables. Percept. Mot. Skills 17, 187-209.

Sommer, M., Rothmayr, C., Dohnel, K., Meinhardt, J., Schwerdtner, J., Sodian, B., and Hajak, G (2010). How should I decide? The neural correlates of everyday moral reasoning. Neuropsychologia 48, 2018-2026.

Stroop, J. R. (1935). Studies of interference in serial verbal reactions. J. Exp. Psychol. 18, 643-662.

Symmonds, M., Bossaerts, P., and Dolan, R. J. (2010). A behavioral and neural evaluation of prospective decision-making under risk. $J$. Neurosci. 30, 14380-14389.

Szpunar, K. K., Watson, J. M., and Mcdermott, K. B. (2007). Neural substrates of envisioning the future. Proc. Natl. Acad. Sci. U.S.A. 104 642-647.

Takezawa, T., and Miyatani, M. (2005). Quantitative relation between conflict and response inhibition in the Flanker task. Psychol Rep. 97, 515-526.

Tanaka, S. C., Doya, K., Okada G., Ueda, K., Okamoto, Y., and Yamawaki, S. (2004). Prediction of immediate and future rewards differentially recruits cortico-basal ganglia loops. Nat. Neurosci. 7, 887-893.

Tobler, P. N., O’Doherty, J. P., Dolan, R. J., and Schultz, W. (2007). Reward value coding distinct from risk attitude-related uncertainty coding in human reward systems. J. Neurophysiol. 97, 1621-1632.

Tom, S. M., Fox, C. R., Trepel, C., and Poldrack, R. A. (2007). The neural basis of loss aversion in decisionmaking under risk. Science 315, 515-518.

Ullsperger, M., and von Cramon, D. Y. (2001). Subprocesses of performance monitoring: a dissociation of error processing and response competition revealed by event-related fMRI and ERPs. Neuroimage 14, 1387-1401.

Van Leijenhorst, L., Gunther Moor, B., Op De Macks, Z. A., Rombouts, S. A., Westenberg, P. M. and Crone, E. A. (2010). Adolescent risky decision-making: neurocognitive development of reward and control regions. Neuroimage 51, 345-355.

Volz, K. G., Schubotz, R. I., and Von Cramon, D. Y. (2003). Predicting events of varying probability: uncertainty investigated by fMRI. Neuroimage 19, 271-280.
Volz, K. G., Schubotz, R. I., and Von Cramon, D. Y. (2004). Why am I unsure? Internal and external attributions of uncertainty dissociated by fMRI. Neuroimage 21, 848-857.

Volz, K. G., Schubotz, R. I., and Von Cramon, D. Y. (2005). Variants of uncertainty in decision-making and their neural correlates. Brain Res. Bull. 67, 403-412.

Volz, K. G., Schubotz, R. I., and Von Cramon, D. Y. (2006). Decision-making and the frontal lobes. Curr. Opin. Neurol. 19, 401-406.

Volz, K. G., and von Cramon, D. Y. (2009). How the orbitofrontal cortex contributes to decision making - a view from neuroscience. Prog. Brain Res. 174, 61-71.

Vorhold, V. (2008). The neuronal substrate of risky choice: an insight into the contributions of neuroimaging to the understanding of theories on decision making under risk. Ann. N. Y. Acad. Sci. 1128, 41-52.

Wager, T. D., Lindquist, M., and Kaplan, L. (2007). Meta-analysis of functional neuroimaging data: current and future directions. Soc. Cogn. Affect. Neurosci. 2, 150-158.

Wager, T. D., Lindquist, M. A., Nichols, T. E., Kober, H., and Van Snellenberg, J. X. (2009). Evaluating the consistency and specificity of neuroimaging data using meta-analysis. Neuroimage 45, S210-S221.

Wallis, J. D. (2007). Orbitofrontal cortex and its contribution to decisionmaking. Annu. Rev. Neurosci. 30, 31-56.

Walton, M. E., Croxson, P. L., Behrens, T. E., Kennerley, S. W., and Rushworth, M. F. (2007). Adaptive decision making and value in the anterior cingulate cortex. Neuroimage 36(Suppl. 2), T142-T154

Wang, J., Conder, J. A., Blitzer, D. N., and Shinkareva, S. V. (2010). Neural representation of abstract and concrete concepts: a meta-analysis of neuroimaging studies. Hum. Brain Mapp. 31, 1459-1468.

Wiebking, C., Bauer, A., De Greck, M., Duncan, N. W., Tempelmann, C., and Northoff, G. (2010). Abnormal body perception and neural activity in the insula in depression: an fMRI study of the depressed "material me". World Journal of Biological Psychiatry 11, 538-549.

Wiebking, C., De Greck, M., Duncan, N. W., Heinzel, A., Tempelmann, C., and Northoff, G. (2011). Are emotions associated with activity during rest or interoception? An exploratory fMRI study in healthy subjects. Neurosci. Lett. 491 87-92. 
Wischniewski, J., Windmann, S., Juckel, G., and Brüne, M. (2009). Rules of social exchange: game theory, individual differences and psychopathology. Neurosci. Biobehav. Rev. 33, 305-313.

Wittmann, B. C., Daw, N. D., Seymour, B., and Dolan, R. J. (2008). Striatal activity underlies noveltybased choice in humans. Neuron 58, 967-973.

Wollman, M. C., and Antrobus, J. S. (1986). Sleeping and waking thought - effects of external stimulation. Sleep 9, 438-448.

Wu, J. T., Wu, H. Z., Yan, C. G., Chen, W. X., Zhang, H. Y., He, Y., and Yang, H. S. (2011a). Aging-related changes in the default mode network and its anti-correlated networks: a restingstate fMRI study. Neurosci. Lett. 504, 62-67.

Wu, S.W., Delgado, M. R., and Maloney, L. T. (2011b). The neural correlates of subjective utility of monetary outcome and probability weight in economic and in motor decision under risk. J. Neurosci. 31, 8822-8831.

Wunderlich, K., Rangel, A., and O’Doherty, J. P. (2009). Neural computations underlying action-based decision making in the human brain. Proc. Natl. Acad. Sci. U.S.A. 106, 17199-17204.

Wunderlich, K., Symmonds, M., Bossaerts, P., and Dolan, R. J. (2011). Hedging your bets by learning reward correlations in the human brain. Neuron 71, 1141-1152.

Xue, G., Lu, Z., Levin, I. P., Weller, J. A., Li, X., and Bechara, A. (2009). Functional dissociations of risk and reward processing in the medial prefrontal cortex. Cereb. Cortex 19, 1019-1027.

Yeung, N., Cohen, J. D., and Botvinick, M. M. (2004). The neural basis of error detection: conflict monitoring and the error-related negativity. Psychol. Rev. 111, 931-959.

Yoshida, W., and Ishii, S. (2006). Resolution of uncertainty in prefrontal cortex. Neuron 50, 781-789.

Yoshida, W., Seymour, B., Friston, K. J., and Dolan, R. J. (2010). Neural mechanisms of belief inference during cooperative games. J. Neurosci. 30, 10744-10751.

Zamboni, G., Gozzi, M., Krueger, F., Duhamel, J. R., Sirigu, A., and Grafman, J. (2009). Individualism, conservatism, and radicalism as criteria for processing political beliefs: a parametric fMRI study. Soc. Neurosci. 4, 367-383.

Zysset, S., Huber, O., Ferstl, E., and Von Cramon, D. Y. (2002). The anterior frontomedian cortex and evaluative judgment: an fMRI study. Neuroimage 15, 983-991.

Zysset, S., Huber, O., Samson, A., Ferstl, E. C., and Von Cramon, D. Y. (2003). Functional specialization within the anterior medial prefrontal cortex: a functional magnetic resonance imaging study with human subjects. Neurosci. Lett. 335, 183-186.
Conflict of Interest Statement: The authors declare that the research was conducted in the absence of any commercial or financial relationships that could be construed as a potential conflict of interest.

Received: 16 December 2011; accepted: 18 February 2012; published online: 05 March 2012.

Citation: Nakao T, Ohira H and Northoff $G$ (2012) Distinction between externally vs. internally guided decisionmaking: operational differences, metaanalytical comparisons and their theoretical implications. Front. Neurosci. 6:31. doi: 10.3389/fnins.2012.00031

This article was submitted to Frontiers in Decision Neuroscience, a specialty of Frontiers in Neuroscience.

Copyright (c) 2012 Nakao, Ohira and Northoff. This is an open-access article distributed under the terms of the Creative Commons Attribution Non Commercial License, which permits noncommercial use, distribution, and reproduction in other forums, provided the original authors and source are credited. 


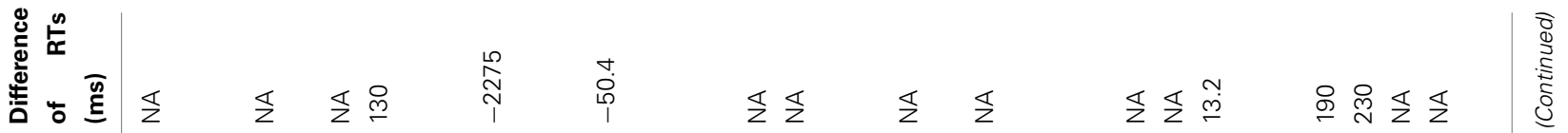

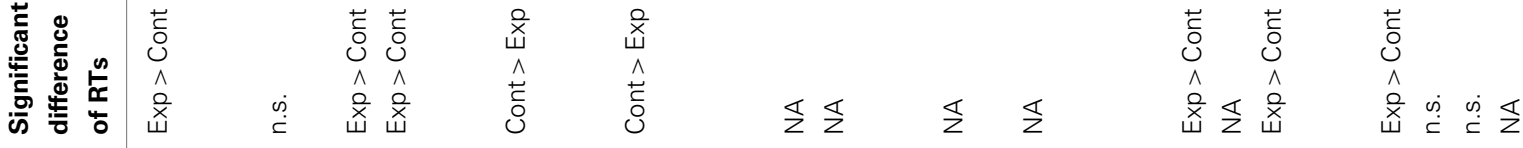

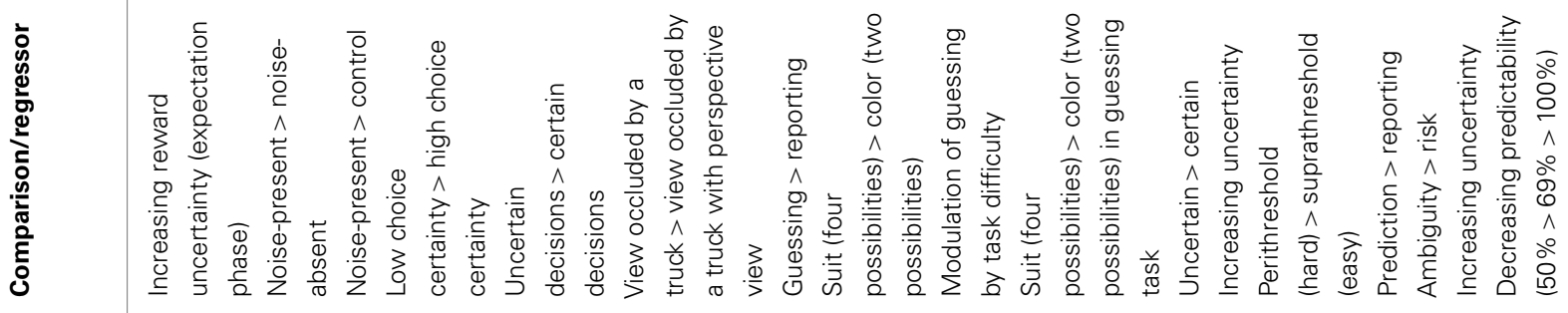

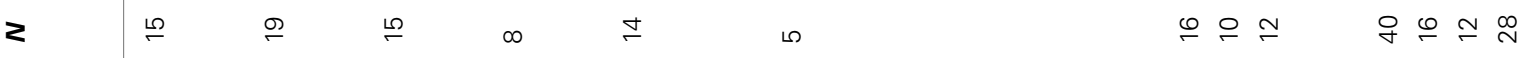

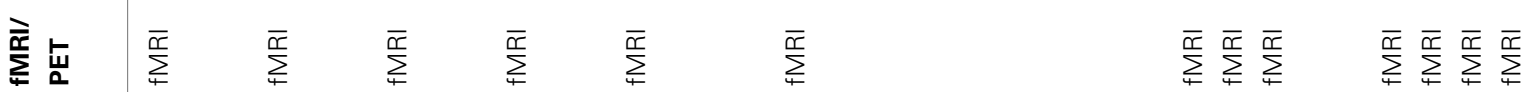

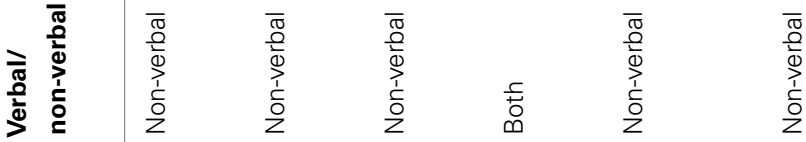

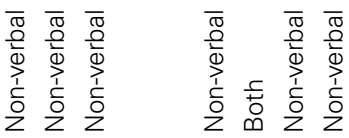

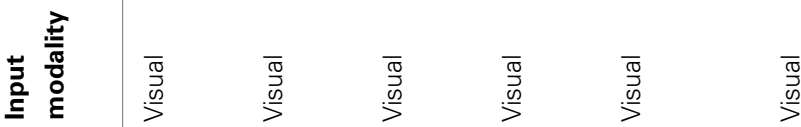

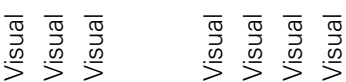
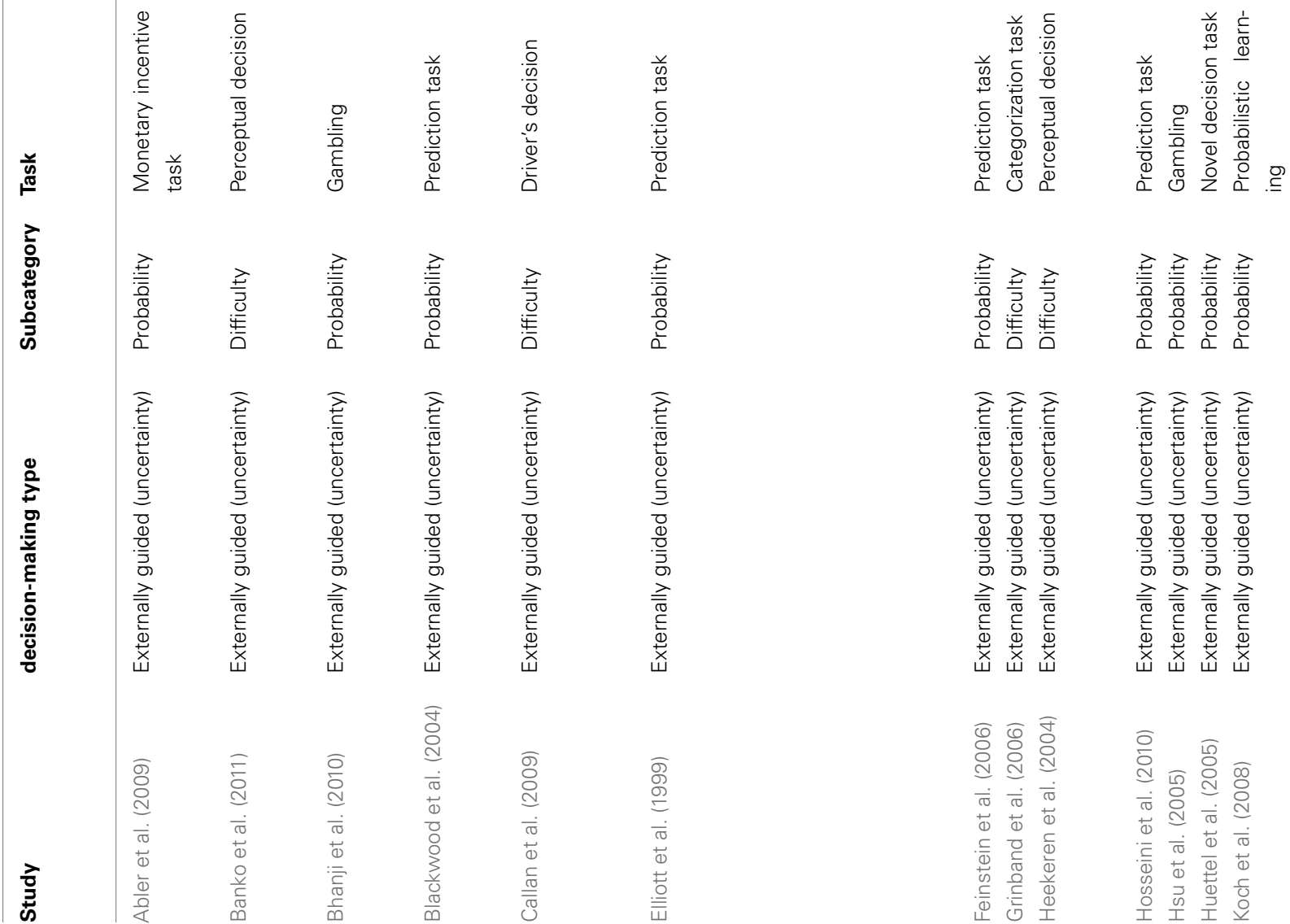


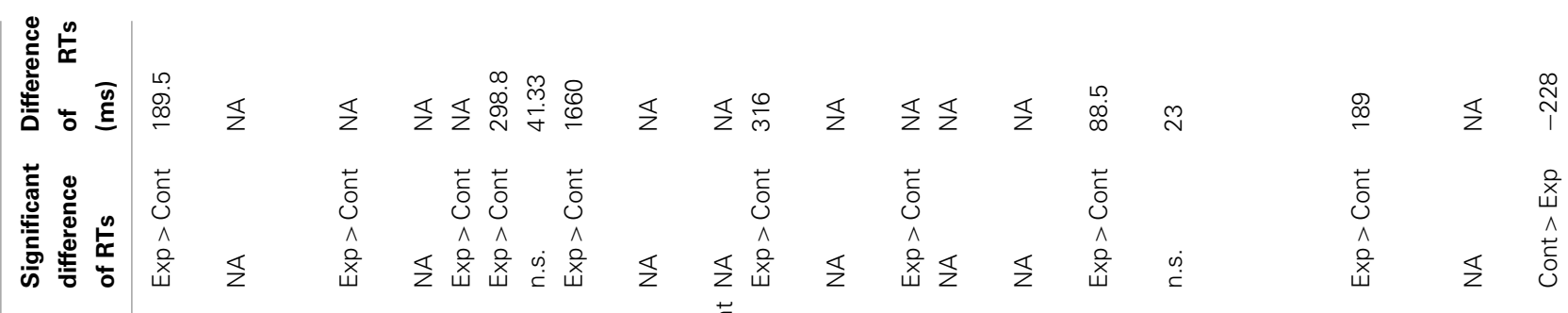

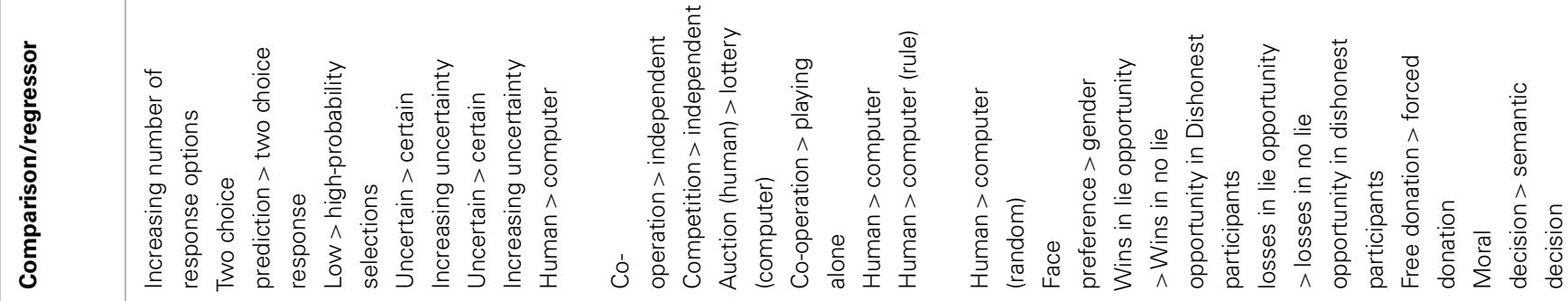

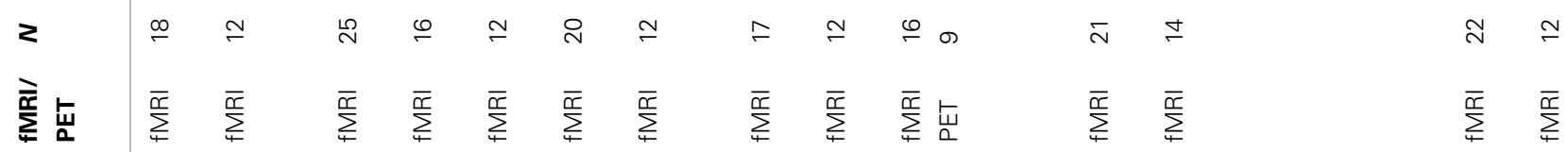

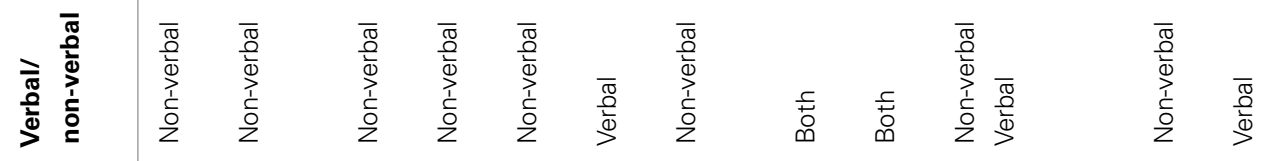

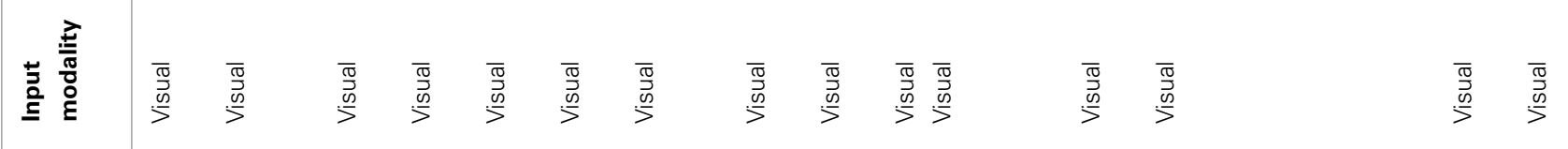

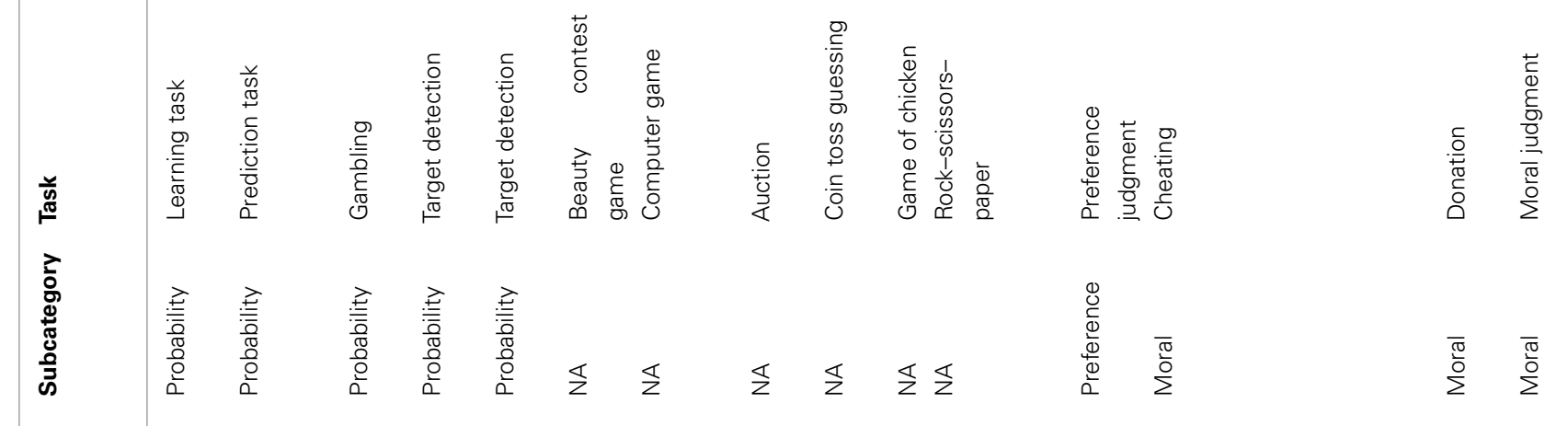
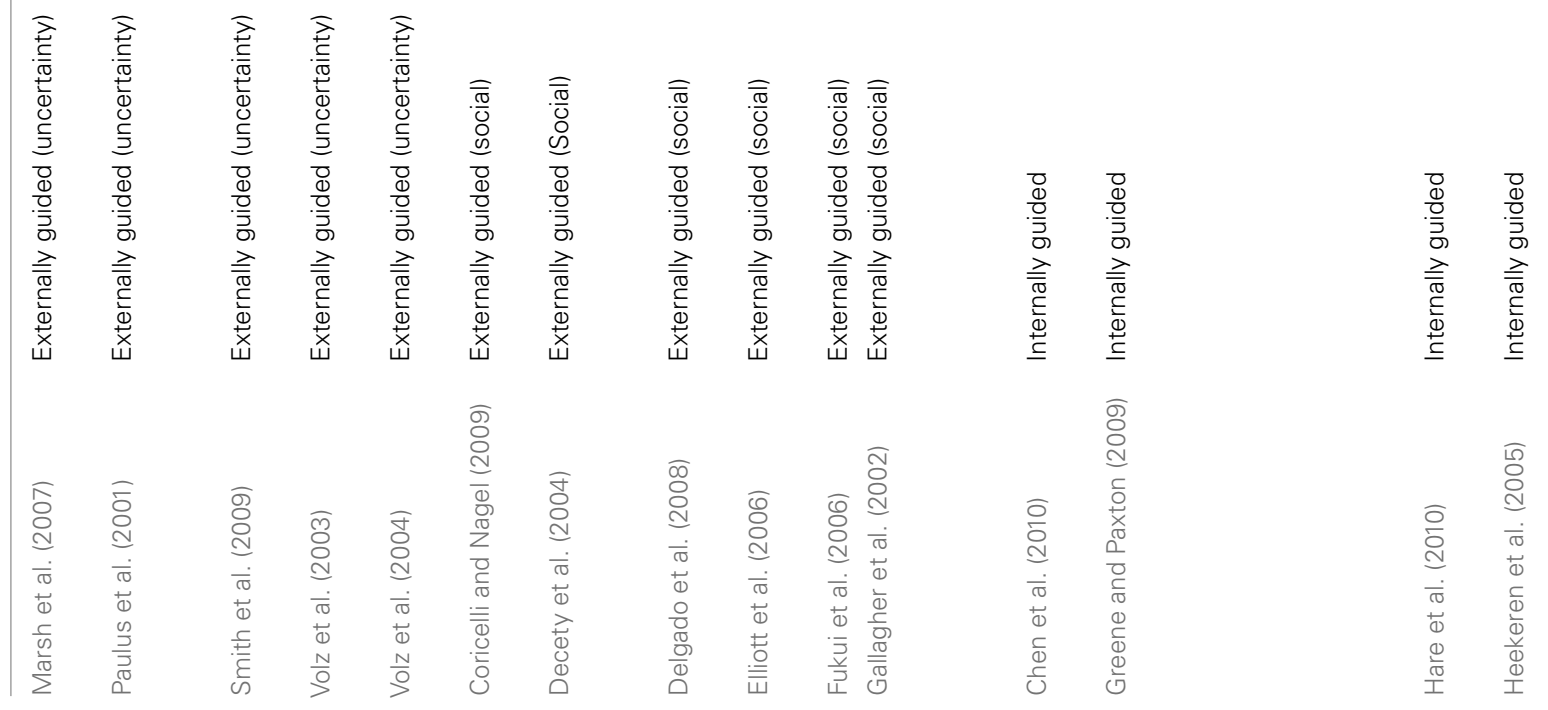


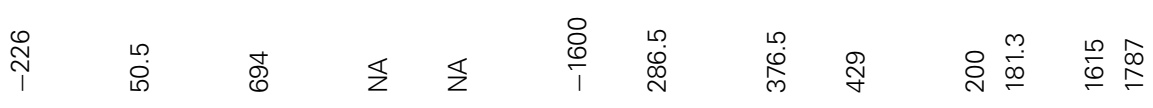

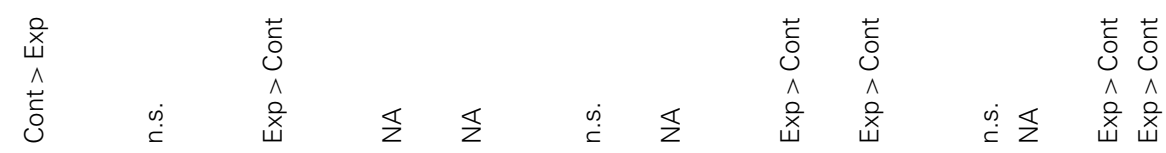
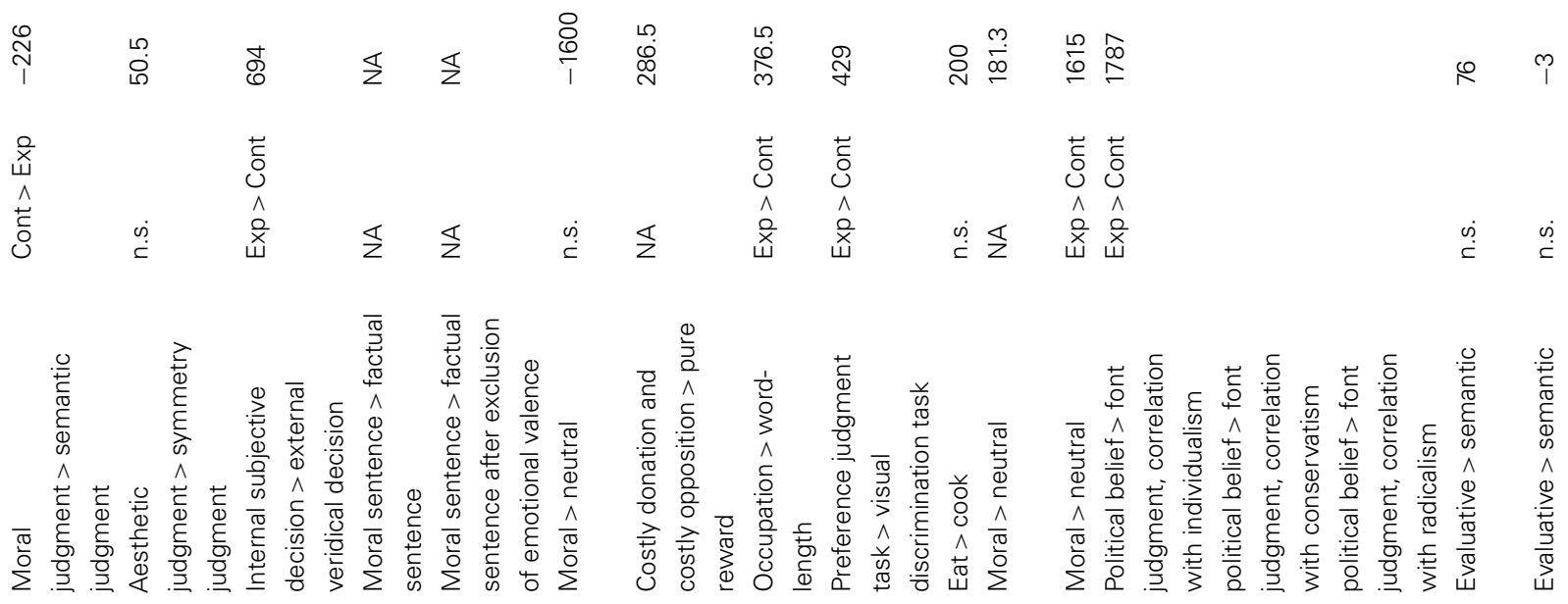

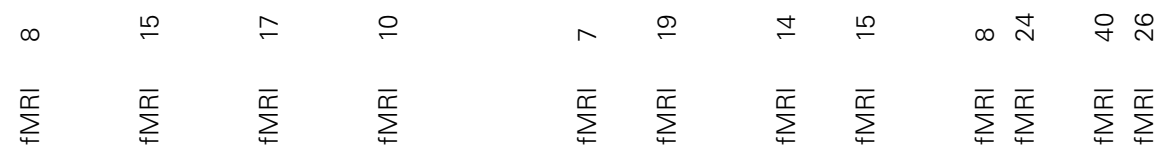

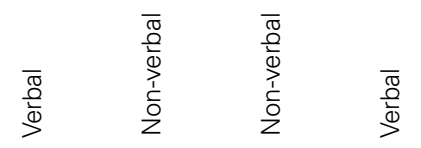

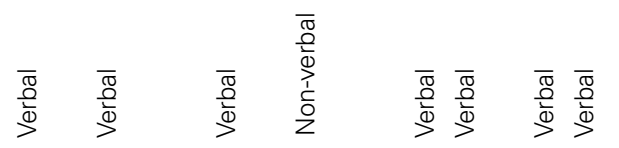

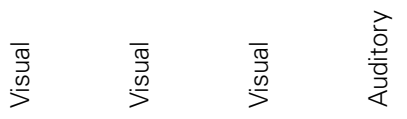

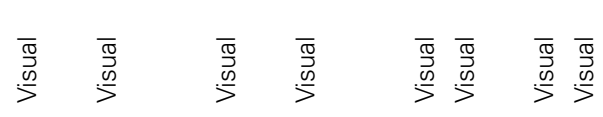

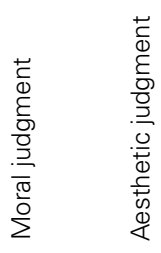

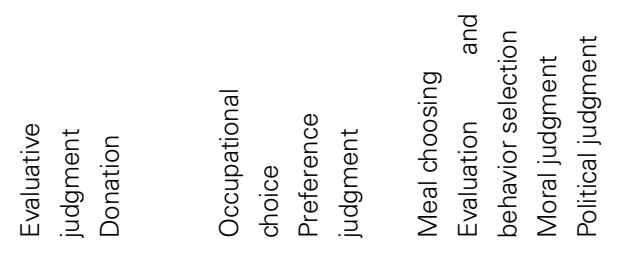

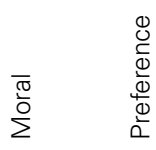

1)

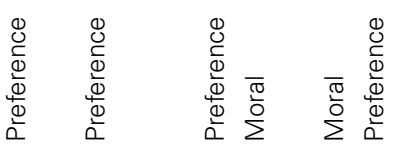

$\stackrel{\infty}{\sim}$

$\sum_{i=1}^{\bar{m}} \sum_{i=1}^{\bar{m}}$

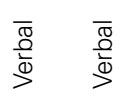

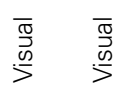

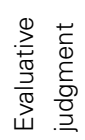

$\stackrel{\bar{\pi}}{\Sigma}$

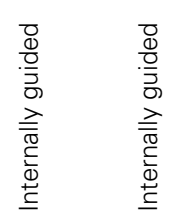

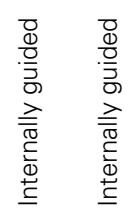
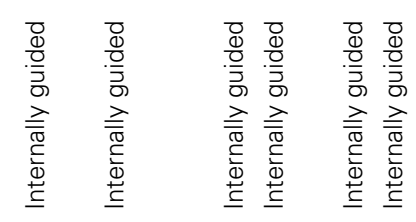

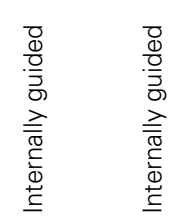
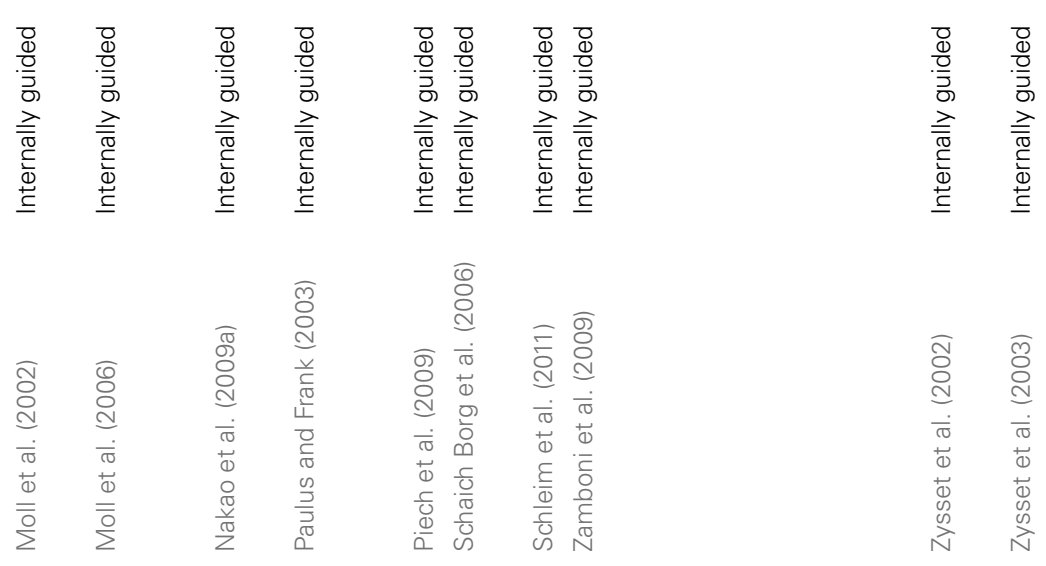

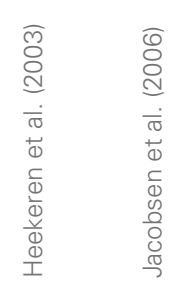
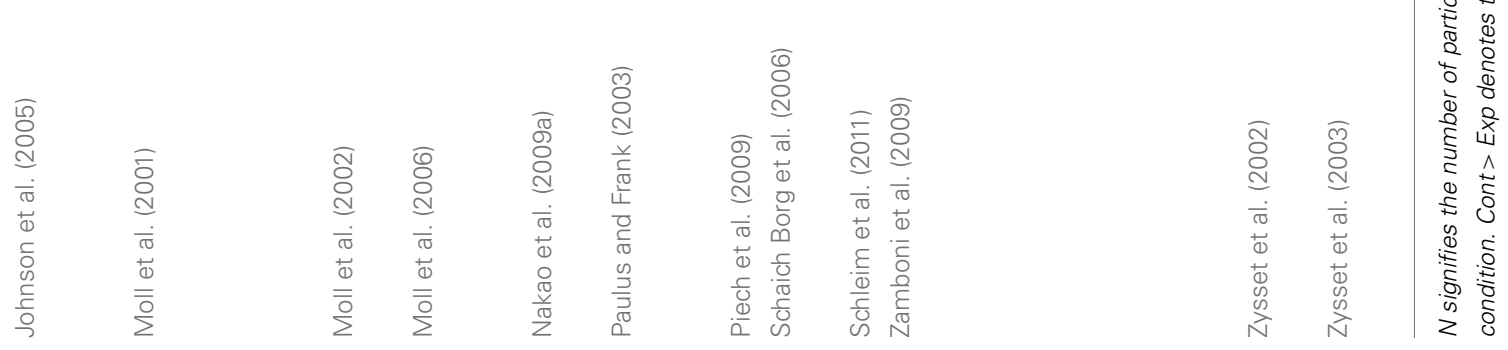


\section{REFERENCES}

Blackwood, N., Ffytche, D., Simmons, A., Bentall, R., Murray, R., and Howard, R. (2004). The cerebellum and decision making under uncertainty. Cogn. Brain Res. 20, 46-53.

Decety, J., Jackson, P. L., Sommerville, J. A., Chaminade, T., and Meltzoff, A. N. (2004). The neural bases of cooperation and competition: an fMRI investigation. Neuroimage 23, 744-751.

Delgado, M. R., Schotter, A., Ozbay, E. Y., and Phelps, E. A. (2008). Understanding overbidding: using the neural circuitry of reward to design economic auctions. Science 321, 1849-1852.
Feinstein, J. S., Stein, M. B., and Paulus, M. P. (2006). Anterior insula reactivity during certain decisions is associated with neuroticism. Soc. Cogn. Affect. Neurosci. 1, 136-142.

Fukui, H., Murai, T., Shinozaki, J., Aso, T., Fukuyama, H., Hayashi, T., and Hanakawa, T. (2006). The neural basis of social tactics: an fMRI study. Neuroimage 32, 913-920.

Hosseini, S. M., Rostami, M., Yomogida, Y., Takahashi, M., Tsukiura, T., and Kawashima, R. (2010). Aging and decision making under uncertainty: behavioral and neural evidence for the preservation of decision making in the absence of learning in old age. Neuroimage 52, 1514-1520.
Huettel, S. A., Song, A. W., and McCarthy, G. (2005). Decisions under uncertainty: probabilistic context influences activation of prefrontal and parietal cortices. J. Neurosci. 25, 3304-3311.

Koch, K., Schachtzabel, C., Wagner, G., Reichenbach, J. R., Sauer, H., and Schlosser, R. (2008). The neural correlates of rewardrelated trial-and-error learning: an fMRI study with a probabilistic learning task. Learn. Mem. 15, 728-732.

Marsh, A. A., Blair, K. S., Vythilingam, M., Busis, S., and Blair, R. J. (2007). Response options and expectations of reward in decision-making: the differential roles of dorsal and rostral anterior cingulate cortex. Neuroimage 35, 979-988.

Paulus, M. P., Hozack, N., Zauscher, B., McDowell, J. E., Frank, L., Brown, G. G., and Braff, D. L. (2001). Prefrontal, parietal, and temporal cortex networks underlie decision-making in the presence of uncertainty. $\mathrm{Neu}$ roimage 13, 91-100.

Smith, B. W., Mitchell, D. G., Hardin, M. G., Jazbec, S., Fridberg, D. Blair, R. J., and Ernst, M. (2009). Neural substrates of reward magnitude, probability, and risk during a wheel of fortune decisionmaking task. Neuroimage 44 600-609. 